This is the version of the article accepted for publication in Archaeological Research in Asia published by

Elsevier: https://www.journals.elsevier.com/archaeological-research-in-asia/

Published under a CC BY-NC-ND license: https://creativecommons.org/licenses/by-nc-nd/3.0/

Accepted version downloaded from SOAS Research Online: http://eprints.soas.ac.uk/26431

[Authors: James Miles, Marc Miyake, Nathan W. Hill]

\title{
Introduction to the Pyu
}

Pyu is an extinct language preserved on inscriptions of an urban civilization located in the dry zone of what is now Burma. Pyu is the oldest Tibeto-Burman language, attested some 300 years before Tibetan and 800 years before Burmese. As such, its rightful place in Tibeto-Burman linguistics would be like that of Latin or Greek in Indo-European comparative linguistics. Nonetheless, until 2018 only eight Pyu inscriptions were available to the learned public and the complete research on the Pyu language amounted to some half dozen relatively short articles. Only about 200 words have been identified, and only a few fundamental points of grammar are known. The inscribed monuments themselves are all badly weathered and poorly conserved. Hence the decipherment of the Pyu language has hardly progressed since the pioneering work of Blagden (1911).

\section{Ongoing projects for the decipherment of Pyu}

After a long drought of Pyu language studies in the West, two recent large research projects have included the decipherment of Pyu as one of their aims. The first is 'From Vijayapurī to Śrïșetra? The Beginnings of Buddhist Exchange across the Bay of Bengal as Witnessed by Inscriptions from Andhra Pradesh and Myanmar', funded by a grant from The Robert H.N. Ho Family Foundation. The second is 'Beyond Boundaries: Religion, Region, Language and the State' (ERC Synergy Project 609823 ASIA), funded by a grant from the European Research Council.

In 2016 members of these two projects joined forces to accomplish their shared aim. Arlo Griffiths and Julian K. Wheatley have created an inventory of the known Pyu inscriptions, assigning a number to each item, represented as PYU x. We use those numbers in this paper: e.g., PYU 8 is Pyu inscription 8. Periods separate line numbers from inscription numbers: e.g., PYU 8.3 is line three of Pyu inscription 8. Griffiths and Wheatley have transliterated the inscriptions using all available documentation including Reflectance Transformation Imaging (RTI) with assistance from Marc Miyake.

Griffiths et al. (2017a) explains the conventions of their transliteration. All transliterations of Pyu in this paper, other than the transliteration of an 1894 eye-copy in Figure 18, are theirs. Griffiths and Miyake have since converted these transliterations into XML which are available at Zenodo (Griffiths et al., 2017b). The XML is viewable online at the École française d'Extrême-Orient's (2017) website which also includes metadata and photographs of the inscribed artefacts.

In November 2016, Griffiths, Wheatley, Miyake, along with Bob Hudson, James Miles and Nathan Hill visited Burma to visually document Pyu inscriptions, the locations of which can be seen in Figure 1. Miles took high-resolution photos of the texts to produce RTI and photogrammetry files. This paper demonstrates the value of RTI for recovering an extinct language in a complex script. 


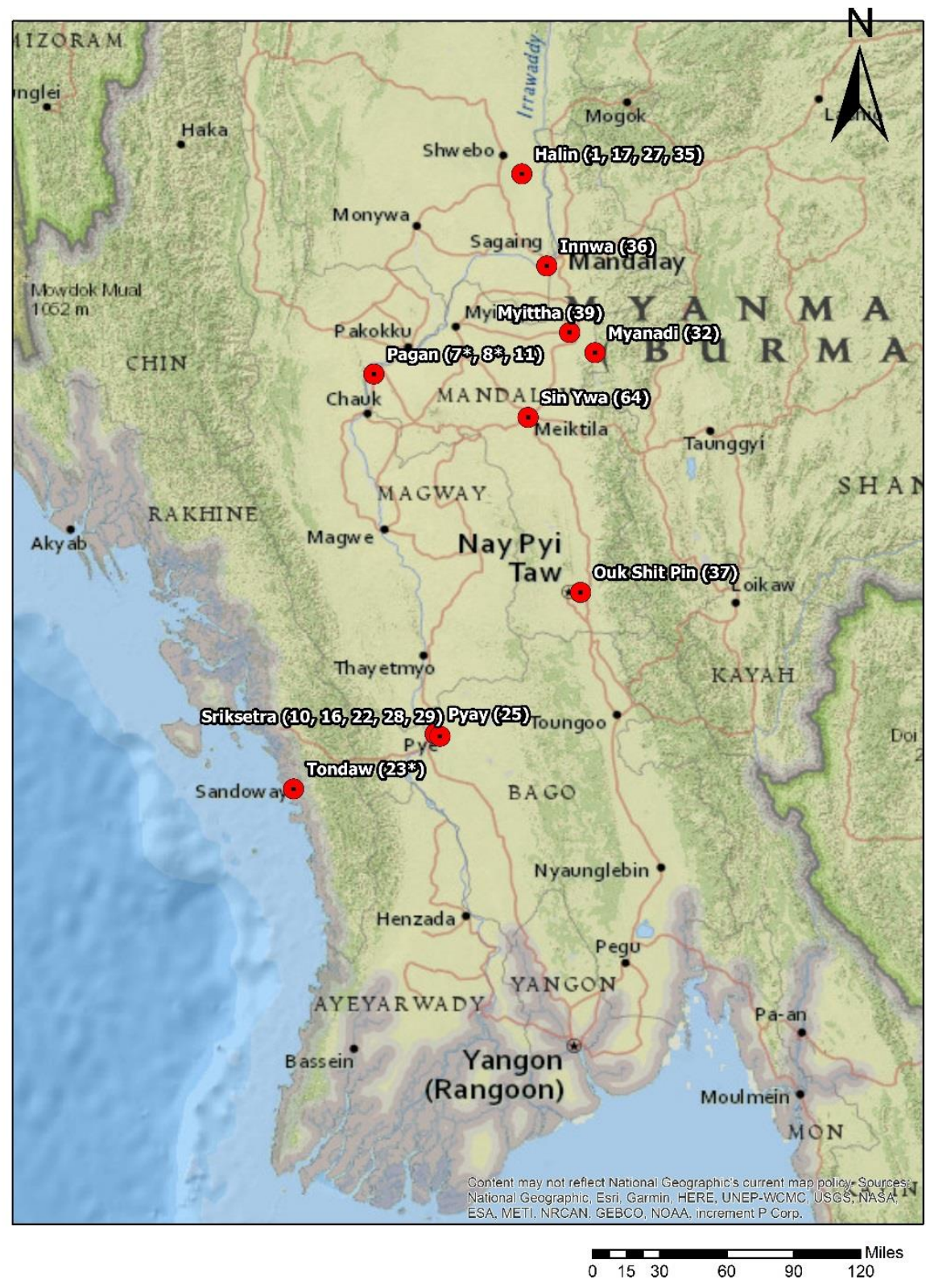

Figure 1. Map location showing the individual locations of each PYU RTI that was captured in Burma 2016. Map data: National Geographic and Esri

\section{Reflectance Transformation Imaging}

Reflectance Transformation Imaging, abbreviated to RTI, is a photographic technique that enables the extraction of subtle surface differences using a system of raking lights. The method was created by Tom Malzbender from Hewlett Packard Laboratories in 2001 (Malzbender et al., 2001) and was intended to provide a new form of texture mapping that produces increased photorealism in threedimensional reconstruction textures. The method has since proved successful in cultural heritage studies in providing enhanced understandings of surface detail that are hard to understand through visual examination (discussed below). Malzbender originally created a mathematical algorithm 
known as Polynomial Texture Mapping (PTM) and the method has since expanded to include a number of different algorithms, under the terminology of RTI (Mudge et al., 2006), to allow for different surface features to be extracted. The most common processing tool still used is PTM.

The first examination of heritage based RTI was undertaken by Malzbender et al. (2001) whereby writing tablets and funerary statuary were examined. Mudge et al. (2006) expanded on this by introducing the method to rock art studies. Both studies proved that the method is a suitable tool for non-contact based recording and provides a clear understanding of 3D shape characteristics. The method was later adopted by the University of Southampton and the University of Oxford in their AHRC RTISAD project (Earl et al., 2011). This was the first major case study for RTI and the team involved examined the potential of the method through the documentation of a number of artefact types that included amphora stamps, paintings, mosaics, coins, graffiti, gravestones, tool and cut marks, pigment details, inscriptions and many more. The method has since strengthened and has expanded to other areas of cultural heritage. These include RTI examinations of forensics (Hamiel and Yoshida, 2007); classical text-based research (Earl et al., 2011); Egyptological examinations (Piquette, 2014); numismatics research (Mudge et al., 2005); rock art engravings (Diaz-Guardamino and Wheatley, 2013); daguerreotypes (Pagi et al., 2017); large statues (Miles et al., 2014); virtual computed tomography datasets (Miles et al., 2016); virtually recorded landscapes (Goskar and Cripps, 2010, Miles, 2016c); and in situ underwater cultural heritage (Selmo et al., 2017).

RTI focuses on the acquisition of images from a fixed position with varying light positions, creating a dataset that captures changing raking light effects. Raking light has been used greatly in the inspection of paintings and objects to gather evidence relating to the relief and surface topography of the material captured (Ruhemann, 1958). The effects of raking light can be seen in day-to-day examinations of landscapes, most notably in the differences seen when landscapes are photographed at different points of the day, with some features been more clearly seen at dawn and dusk, than at high noon. Using low angle light illumination creates strong shadows that enhance the visibility of small topographical changes and is fundamental in how RTI is captured and processed.

The datasets that are produced are an image-based representation of the appearance of a surface under raking light. Digital images are built up of pixels, which are physical points in a raster image that contain red, green, blue and normals of the data captured. Red, Green and Blue refer to the colour detail, and the normals are objects, such as a line or vector that are perpendicular to a given object, showing the direction of the 3D surface of the data captured. With the light direction captured per normal, through the varying number of images that are taken, these surface normals, per image, can be extracted to calculate how a light will interact with the surface normals using a two-dimensional representation of the data captured. Through this method, these surface normals are combined in an interactive tool, whereby a virtual light can be used in open source software (Cultural Heritage Imaging, 2012) to enable a change of lighting direction on a recorded surface, as demonstrated in Figure 2. Through this software, enhancements to the image data can be introduced to enable the surface detail to be visible, where it otherwise would not be. A full explanation can be gained through Cultural Heritage Imaging's (2012) website and in Tom Malzbender's (2001) original paper on the subject. 


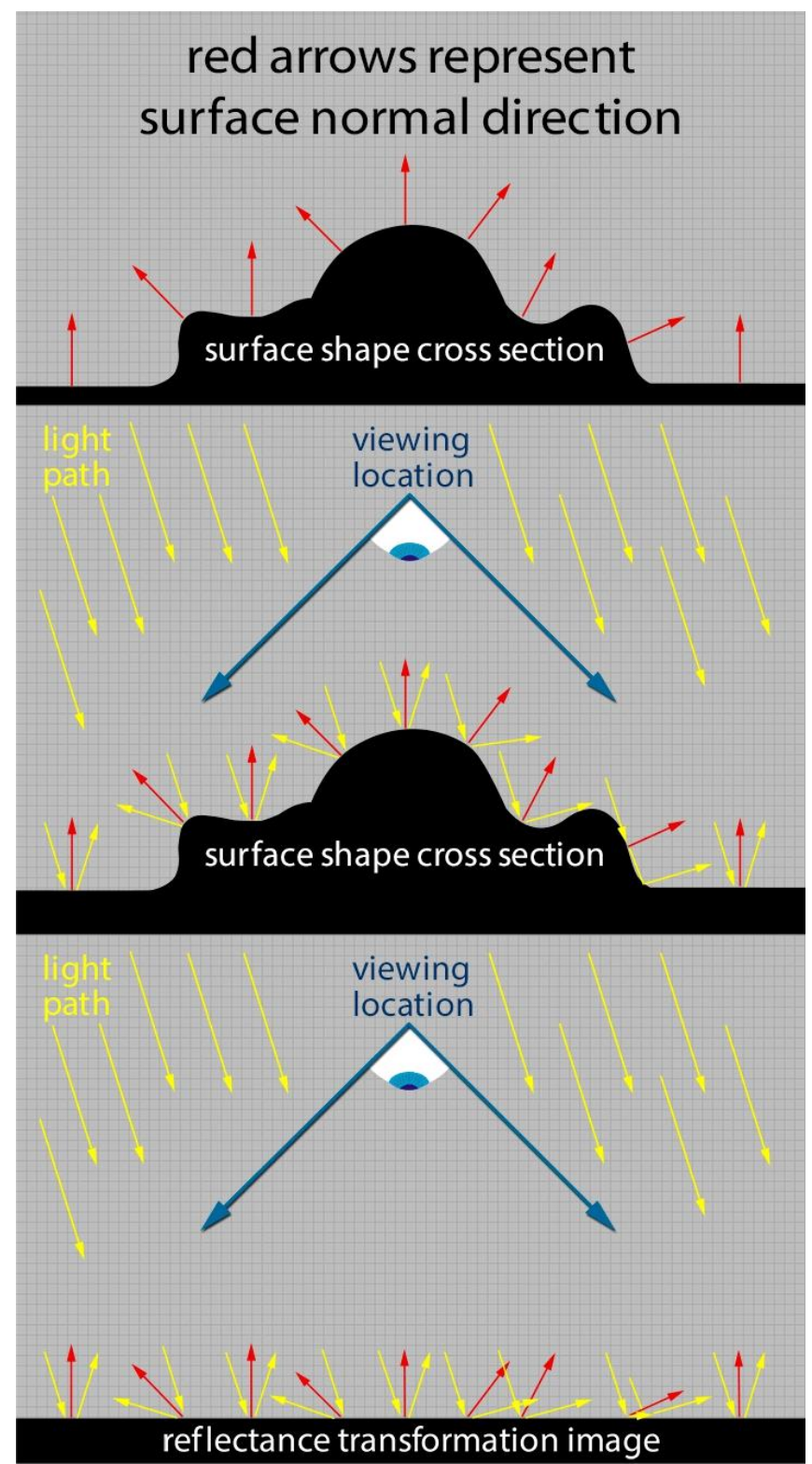

Figure 2. The mathematical calculation of RTI. The first image represents the surface normals of a captured object. The second image represents the direction of the light paths per normal from the external light source for the RTI, per pixel. As the light directions are known per pixel, the RTI software is able to remove the surface shape, and calculate how the luminance of a new virtual light will interact with the record features, as shown in the third image. Images sourced from Cultural Heritage Imaging (2012)

Each RTI resembles a single, two-dimensional photographic image. With the introduction of reflectance information, derived from the three-dimensional shape of the recorded subject, each RTI dataset is able to calculate per pixel how light will reflect off the subject. This allows the interactive light to be introduced, to what appears to be a two-dimensional image, creating what is effectively termed as a two-and-half-dimensional dataset. Importantly, the fitted interactive image is not a composite image, rather, each of the original photographs are stored within the file and are displayed when specific views are requested (Pagi et al., 2017, 116). It is through this virtual light and the different rendering modes available (explained in the Glossary), that examinations can take place to extract information from the data that would otherwise be difficult to obtain.

RTI is recorded through two different ways. The first is through a dome setup where each of the individual lights needed in capturing are provided in set known positions. The camera and recorded 
object are placed in a stationary position, with the processing software applying the set location of the lighting positons to the RTI dataset. An example of this recording setup is shown in Figure 3 and is useful when capturing a number of small items in a single location.

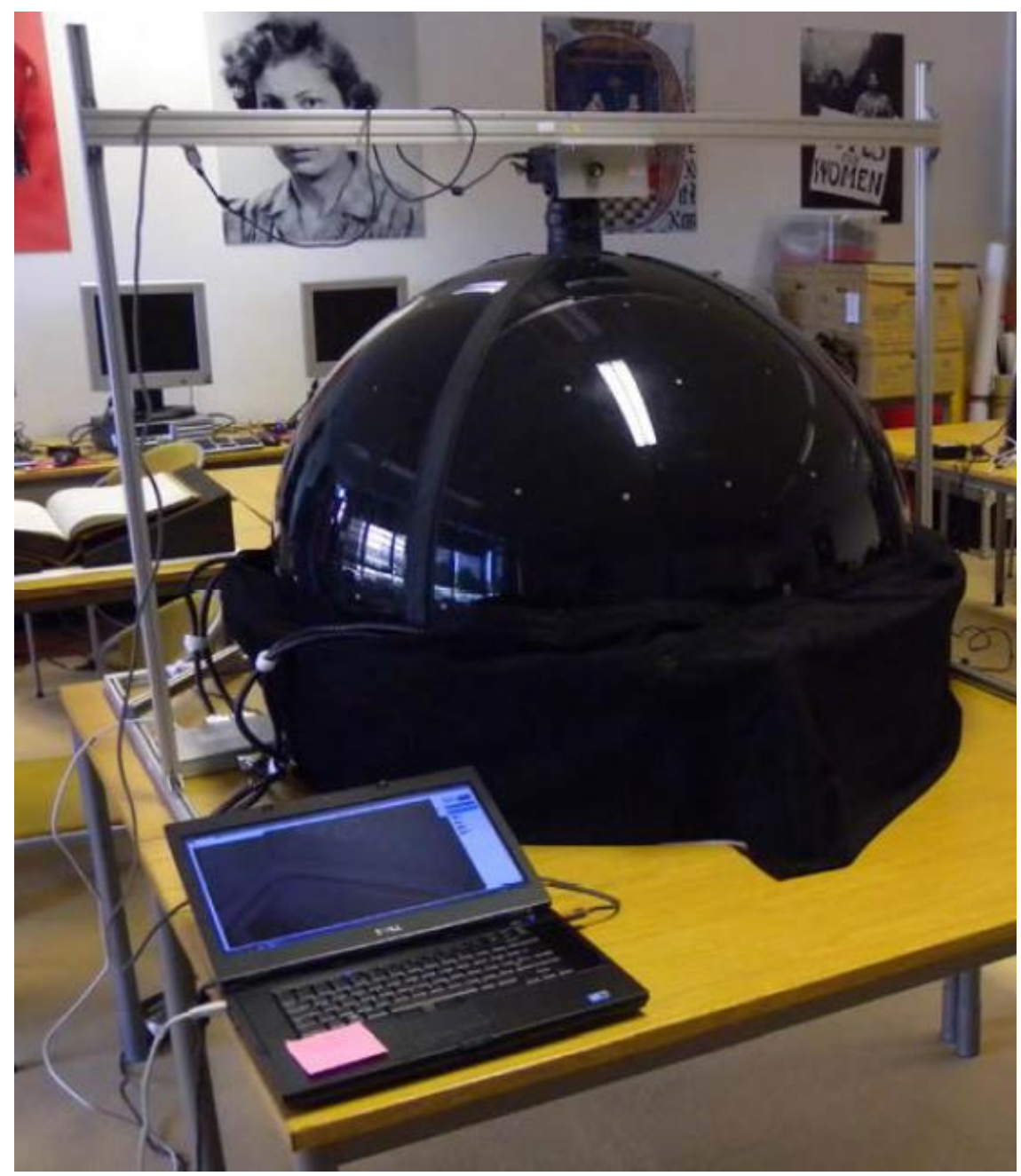

Figure 3. RTI dome capture. The dome was produced during the AHRC funded RTISAD project. The camera can be seen at the top of the dome, with a series of lights highlighted as small spots on the dome surface. The dome is controlled by a laptop, with images captured in sequence, with the individual lights being switched on and off as required. Photo by Hembo Pagi

The second method, and the one used in our work in Burma, is known as highlight RTI and is used when working in areas where the dome is hard to transport, and when the object is larger than the space of the dome. This method follows the same recording approach as before, but utilises a reflective ball and an external light source. The reflective ball is placed parallel to the recorded object and a series of images are captured with the external light. As the light position changes, a white mark is highlighted in the reflective ball and this is used to calculate the location and distances of the necessary light positions. As with before, the camera, recorded object, and the reflective ball must remain in the same position. As the calculations that are made are based on the pixel information of the images, any changes in position will affect the displayed results. The highlight method is useful when working on large items and when working whilst on fieldwork. The camera is always set to allow the external light to be recorded and requires the settings of the camera to remove ambient lighting. Recording outside in the sun is therefore possible but this requires an adaption of the recording methodology. 
The method works best when recording linear features due to the mathematical algorithms used in the processing. Curved objects can be recorded but difficulties may arise in analysing the data due to the curvature of the surface. Further problems may arise due to additional shadowing, such as a raised edge, introducing unwanted elongated shadows on the surface. In such circumstances, the only shadows that should be included are those from the external light source, and it is best to adapt the recording methodology to focus on key areas. The method is however adaptable and can be used on very small areas, as well large surfaces. An example of the highlight RTI recording setup is shown in Figure 4. Figure 5 also provides an overview of the highlight results of the reflective ball once the data has been processed in the RTI software. Each image that was used in our fieldwork in Burma was colour corrected and the lens distortion of each image was removed to give an accurate representation of the surface detail.

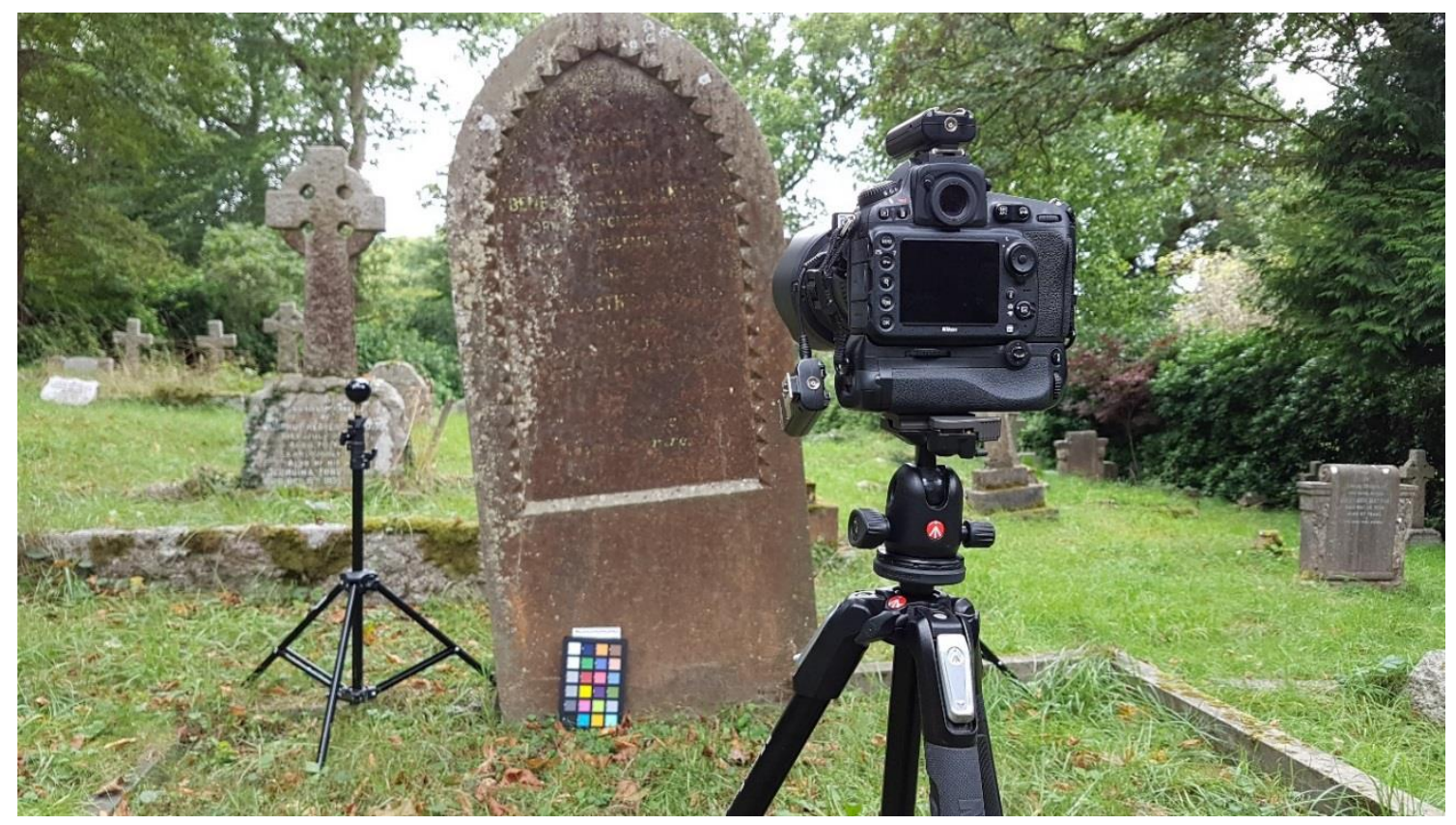

Figure 4. Highlight RTI setup capturing a gravestone at Burley, New Forest, UK. The camera and gravestone are in a stationary position, with the reflective ball found on the left hand side, parallel to the gravestone. An external light source is then moved in a dome shape around the gravestone and successive images are captured. Photo by James Miles 


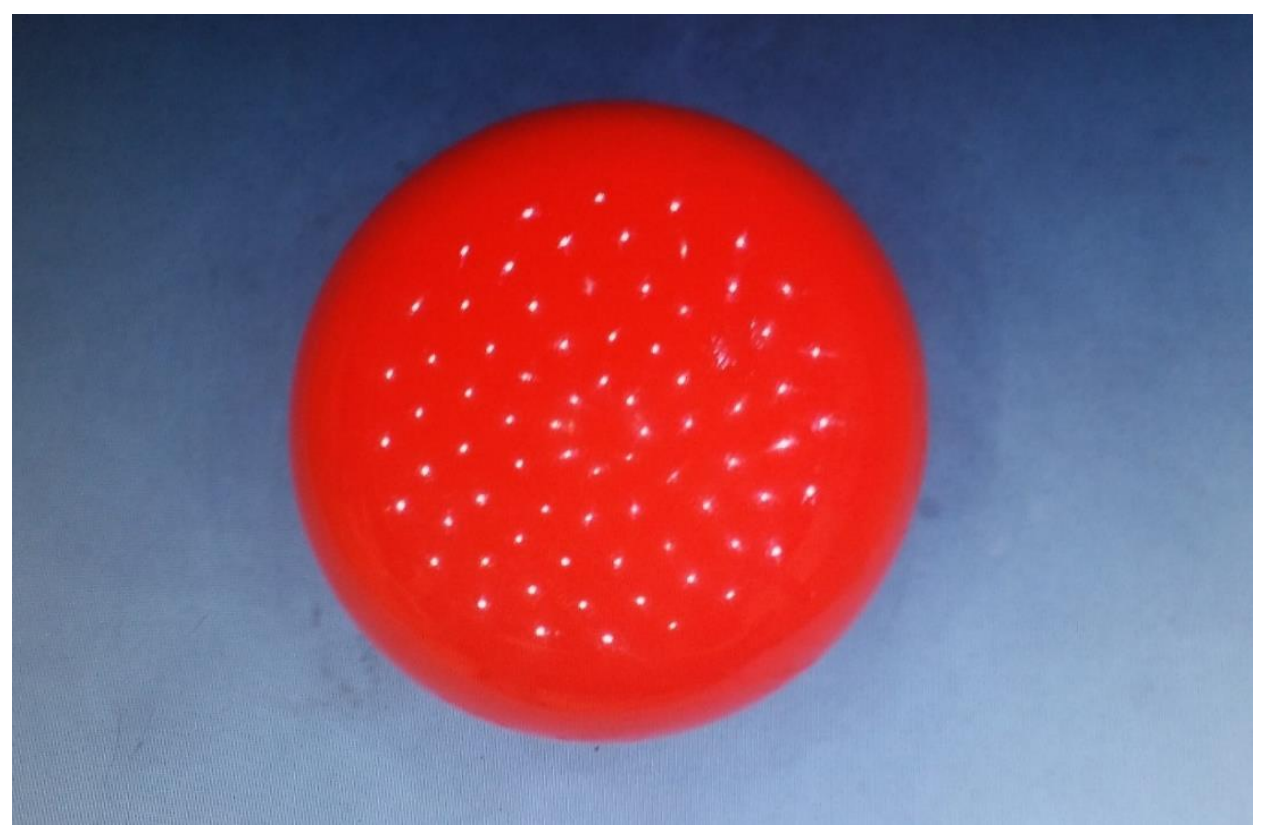

Figure 5. Multiple image captures using the highlight RTI method, with each white spot representing a light location. Photo by James Miles

The work that follows is an overview of the RTI documentation that took place in Burma in November 2016, where over twenty-one PYU inscriptions where recorded using the highlight RTI method. The total number of RTI datasets captured were over seventy. The two examples that are discussed provide an overview of two different recording setups used. Each recording methodology differs due to the environment in which they were captured, with each providing new insights into the Pyu transliteration that have taken place.

\section{Pyu example 1: Kubyaukgyi}

The most famous Pyu inscriptions (PYU 7 and 8) are on the two pillars collectively known as the Kubyaukgyi inscription. The pillars contain references to terminus a quo dates: two (PYU 7 and 8) to a lunar year corresponding to 1112 or 1113 CE. Dr. Emil Forchhammer discovered the pillars in Myinkaba south of Pagan (Duroiselle, 1919, 1). They are often erroneously called the Myazedi inscription because the pillar with PYU 7 and two pieces of the pillar with PYU 8 were found by the modern Myazedi stupa which long postdates the pillars. The other two pieces of the pillar with PYU 8 were at the nearby Kubyaukgyi temple. PYU 8 ( 2.15 metres high) is one and a half times as tall as PYU 7 (1.42 metres). Each pillar has four sides, and each side has an inscription in a different language: Old Burmese, Pali, Old Mon, and Pyu. The two sets of four inscriptions are identical with minor exceptions: PYU 8 has subscript consonants in a few words, whereas PYU 7 does not. The content in each language is, however, marginally different, indicating that the non-Pyu texts are not direct keys to the meaning of PYU 7 and 8. Nonetheless, the Kubyaukgyi inscription is often regarded as the Rosetta Stone of Burma. It is the most studied Pyu inscription. Blagden's (1911) decipherment of the meaning of the Kubyaukgyi, refined in Blagden (1919), is the foundation of Pyu language studies and still remains valid after a century. According to Blagden, the Kubyaukgyi is a record of the construction of a Buddhist shrine and the donation of three villages of slaves. Today PYU 7 is in the Pagan Museum (Figure 6), and PYU 8 has been reassembled outside the Myazedi pagoda. 


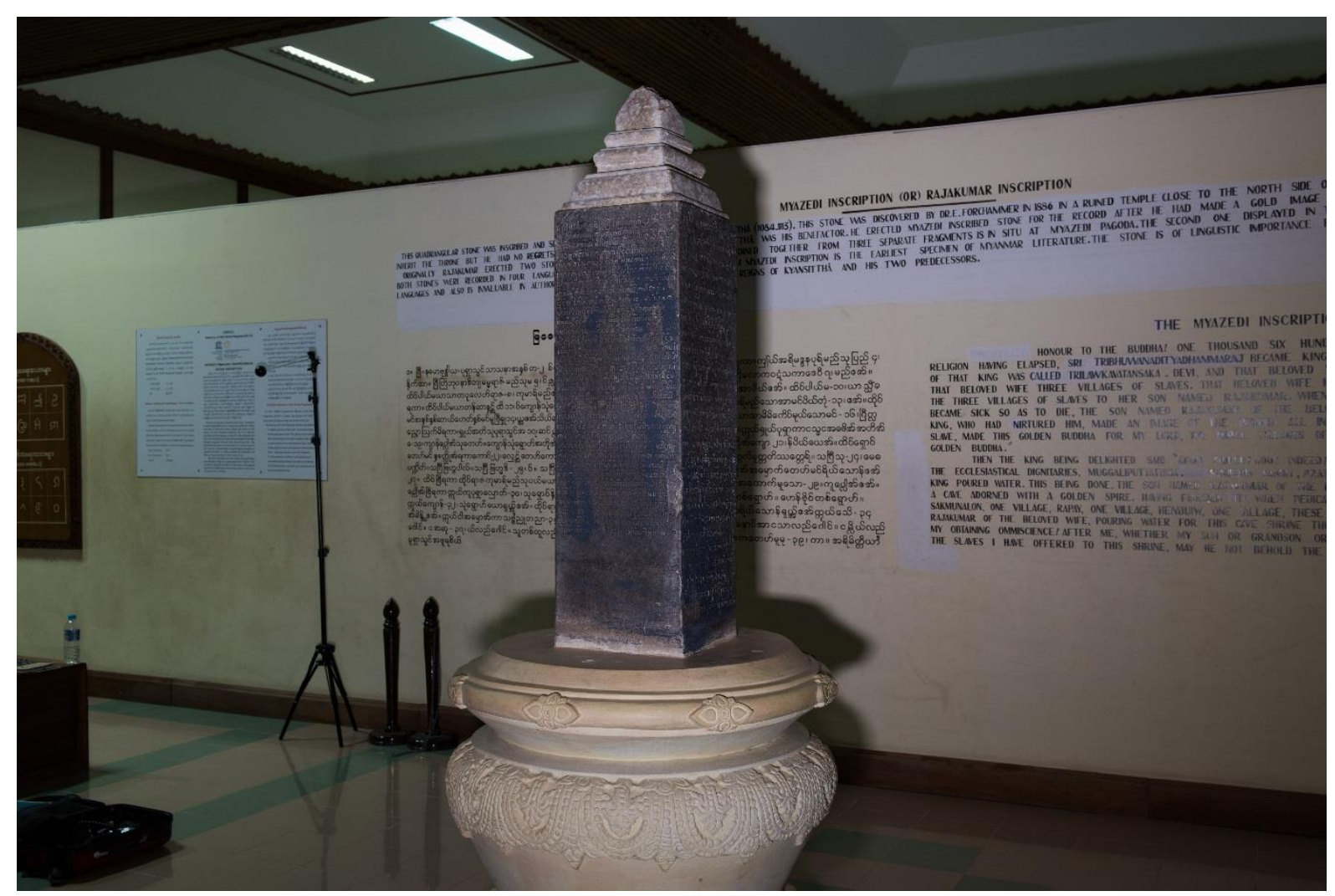

Figure 6. PYU 7 found in the Pagan Museum. Photo by James Miles

The PYU 8 inscription discussed below is housed in a small caged area and the space around the inscription is limited. As such, using the highlight RTI method, a series of RTI datasets were captured, separating each panelled inscription into four to five sections. This allowed the limited space to be utilised to produce the best RTIs possible. Figure 7 provides an overview of the limited space in which the inscriptions are housed, with Figure 8 providing an overview of the RTI results of part of the Pyu inscription. 


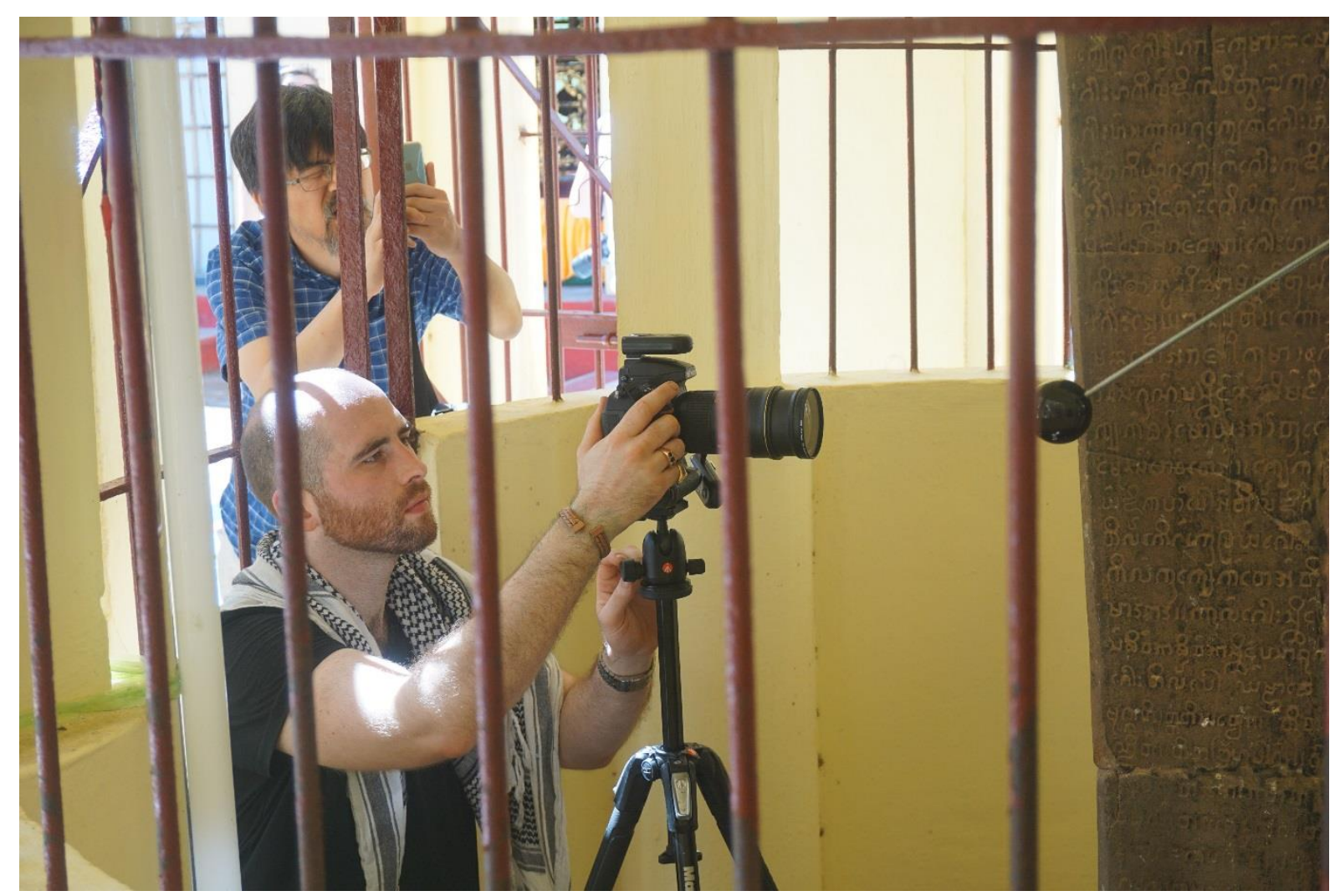

Figure 7. James Miles setting the camera into position for the RTI capture of PYU 8, in the limited space in which the inscriptions are housed. The reflective ball is suspended in the air through a tripod support and is used to capture the light positions of the external light source. Photo by Julian K. Wheatley.

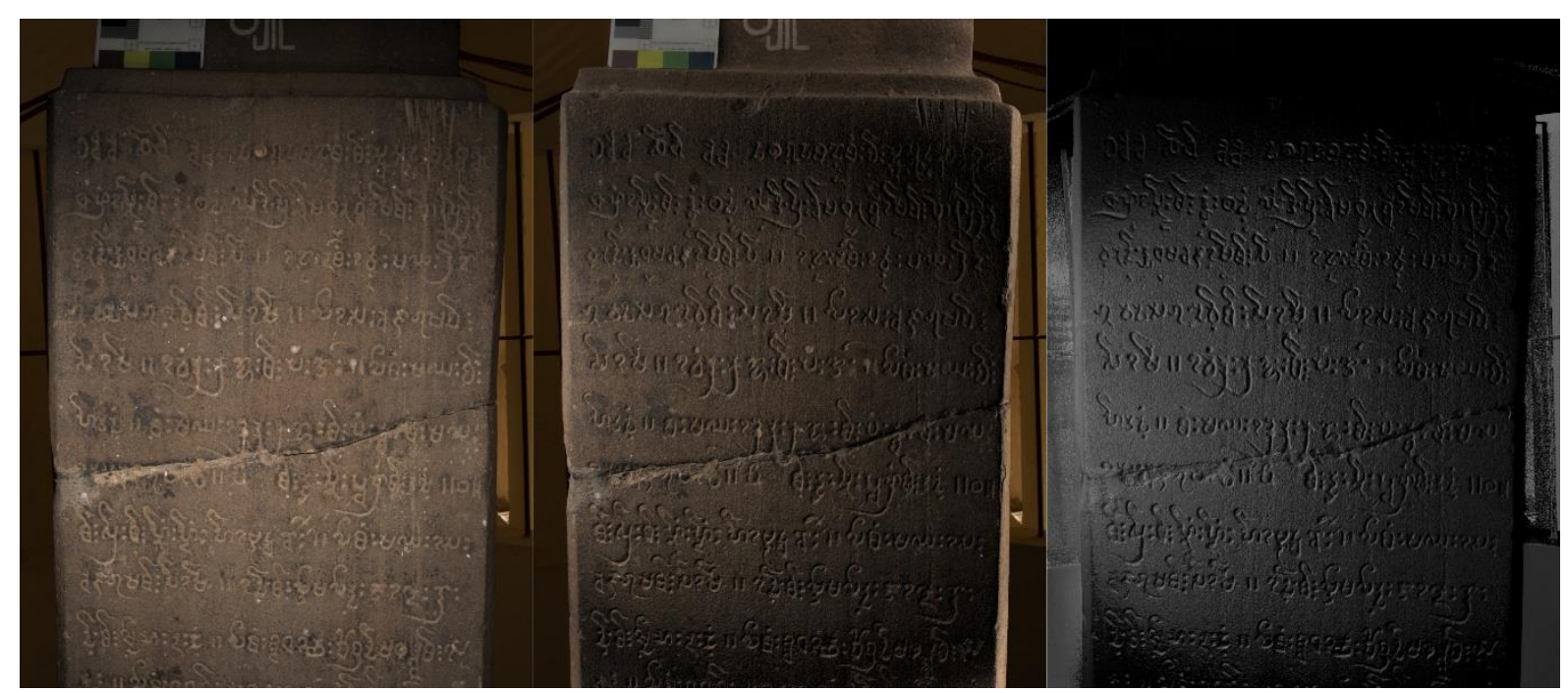

Figure 8. Pyu 8. The left image provides an overview of the Pyu inscription under normal lighting conditions. The middle image provides an RTI example of the inscription using diffuse gain. The right image provides an RTI example of the inscription using specular enhancement. Photo by James Miles 
Pyu was written in an Indic script. Each syllable was represented as a cluster of phonetic symbols. Symbols for syllable-final consonants were located in subscript position as shown in Figure 9

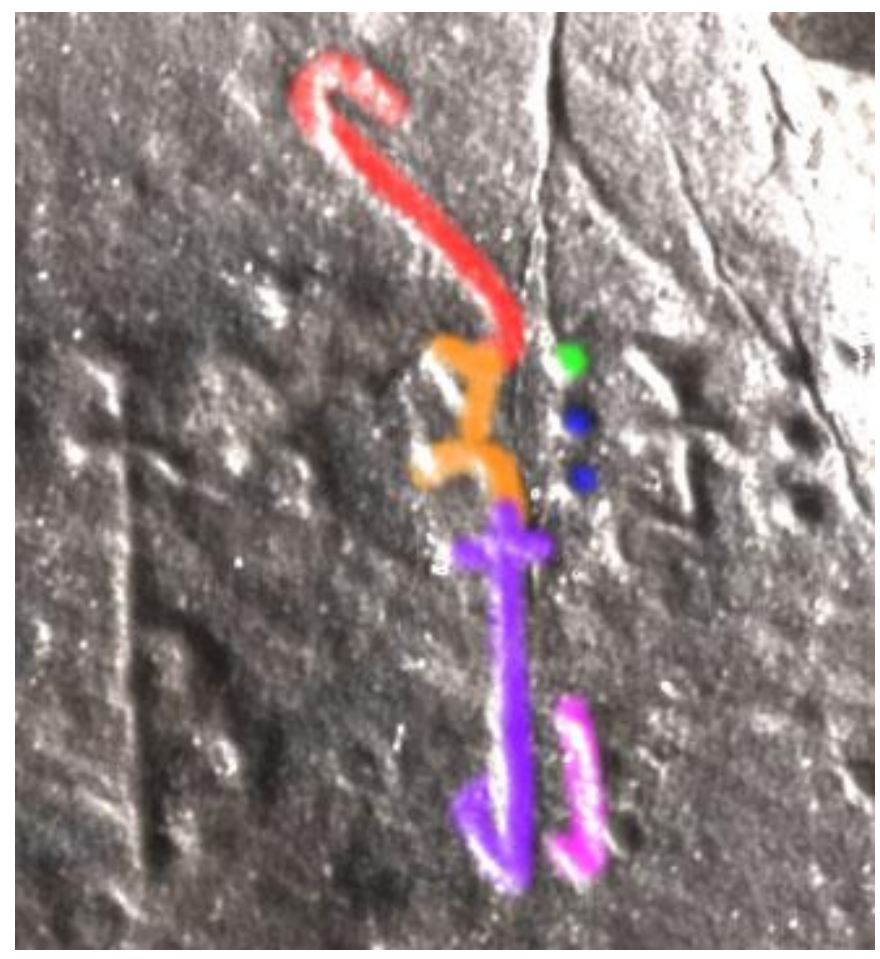

Figure 9. nkir.ṃh, a typically complex syllable from PYU 12 in RTI in specular enhancement rendering mode. $i$ (red) is a vowel symbol attached to a ligature of the consonant symbols $n$ (orange) and $k$ (purple) next to the diacritics $\dot{m}$ (one dot; green) and $h$ (two dots for $/ h /$; blue) and above the subscript consonant symbol $r$. (pink).

We transliterate subscript consonant symbols with following middle dots: e.g., $r$ - represents a subscript $r$.

Photographs of estampages of PYU 7 and 8 have been published several times (e.g., Figure 10 Figure 13), but none reveal the subscript consonant symbols of PYU 8 as clearly as our RTI data. 
2.7.

1. 378 .

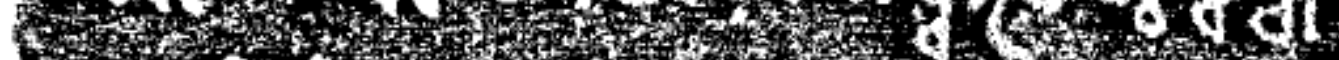

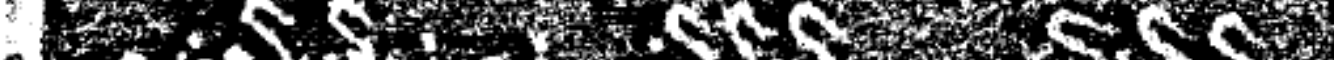

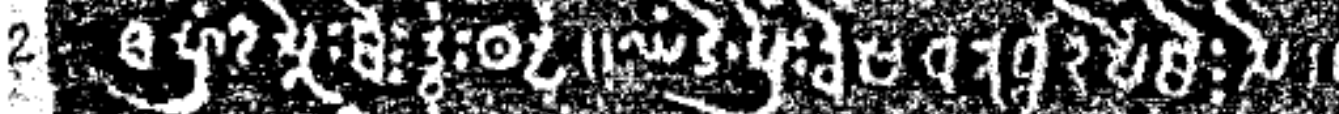

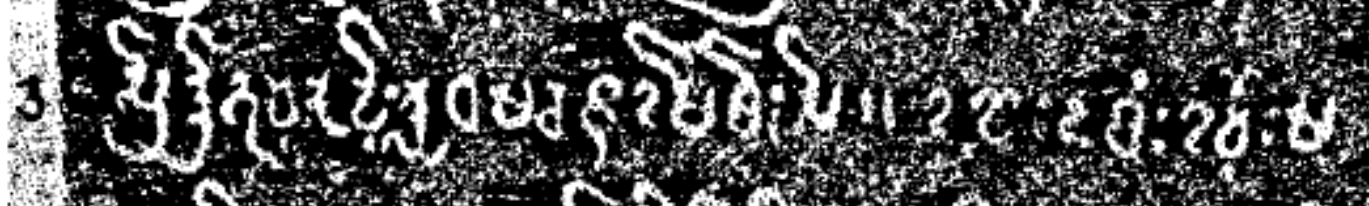

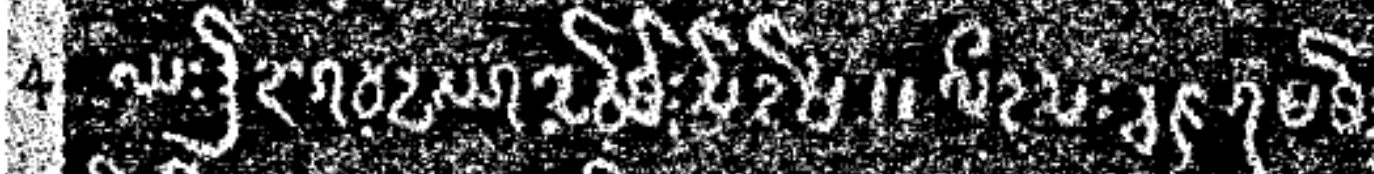

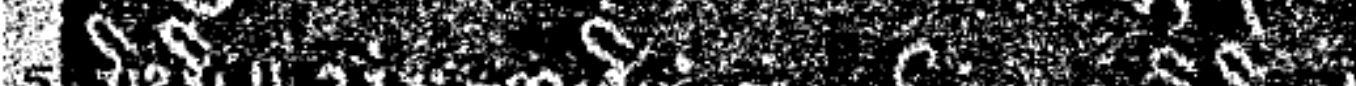

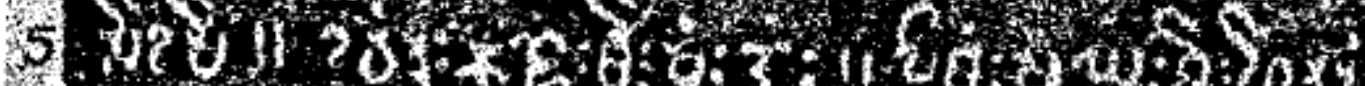

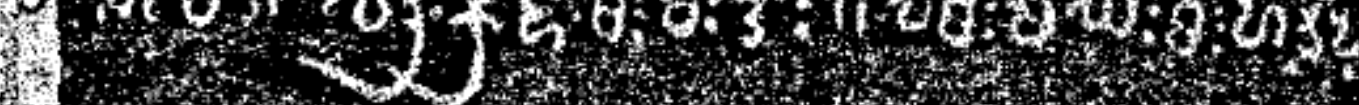

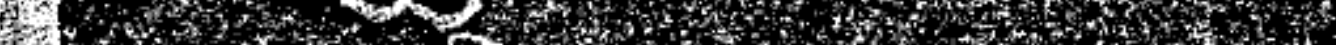

(1)

T. I)

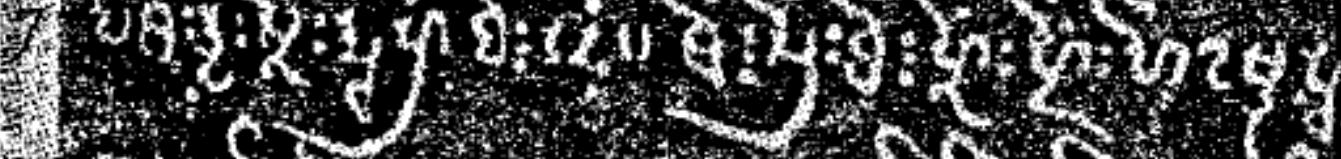

If

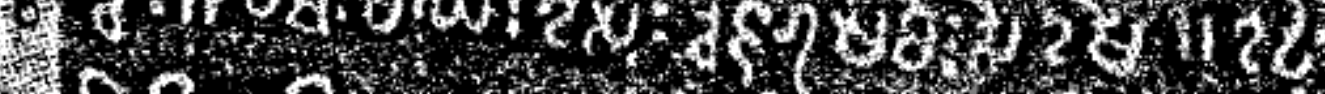

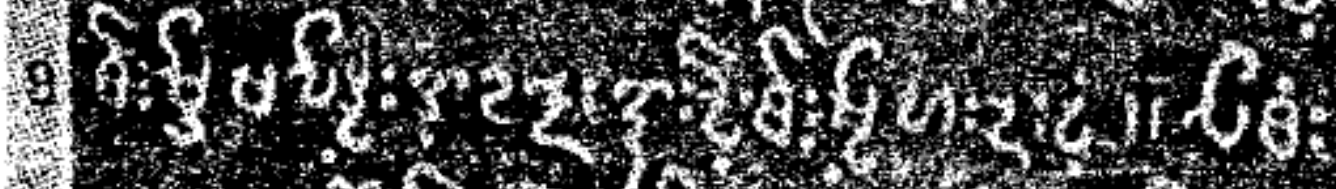

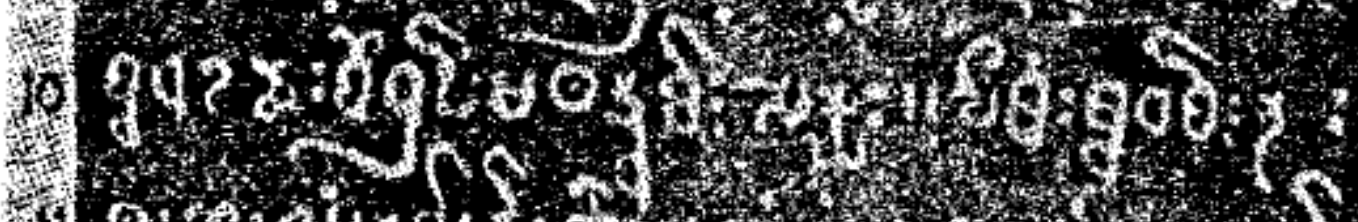

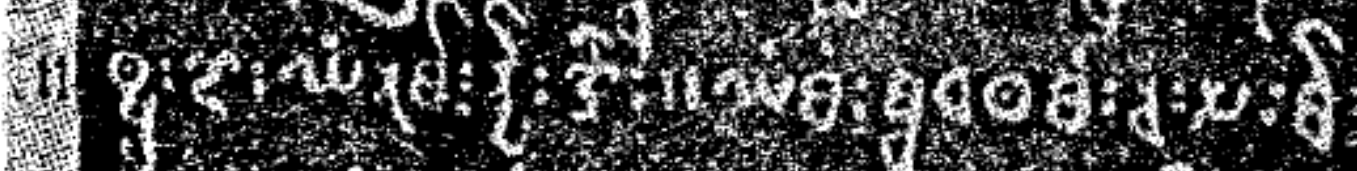

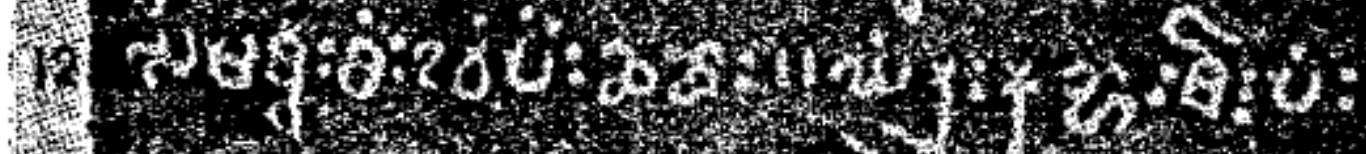

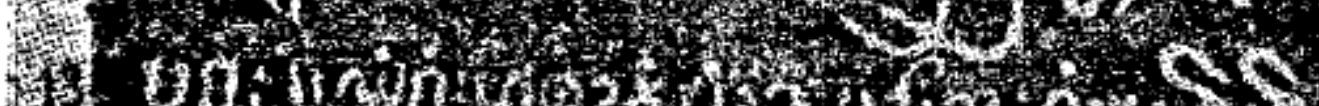

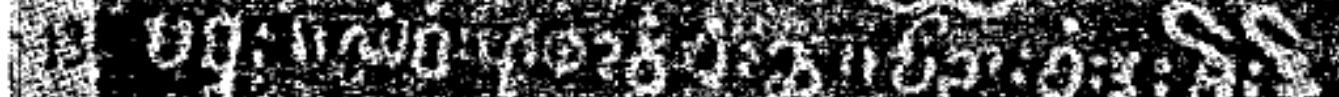

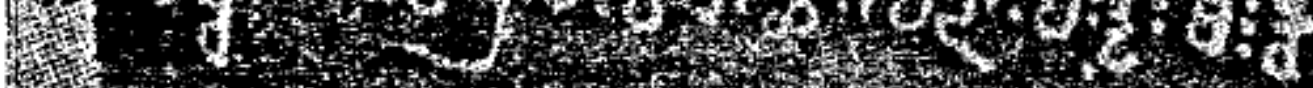

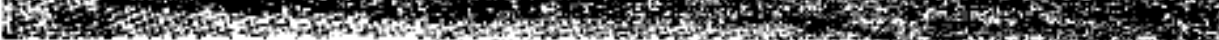




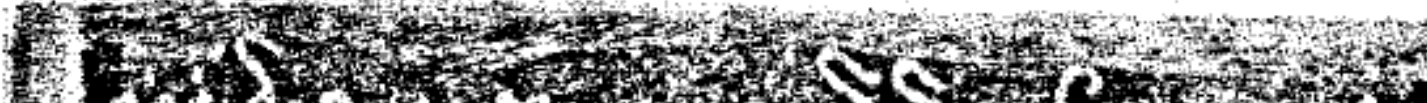

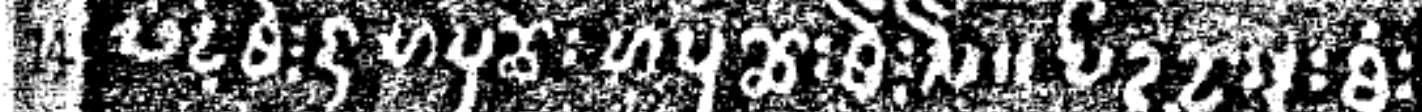

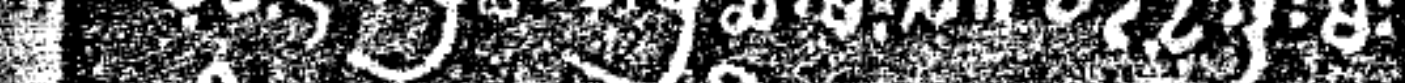

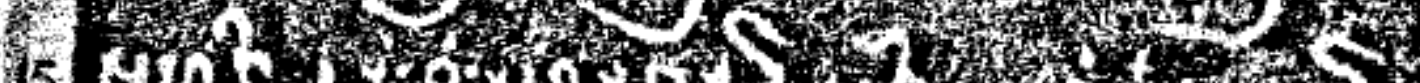

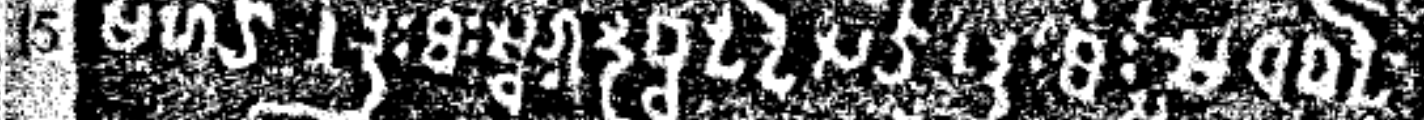

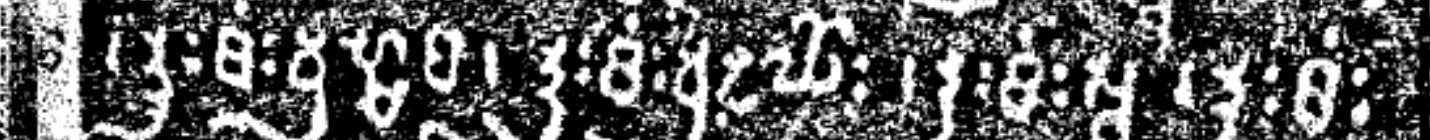

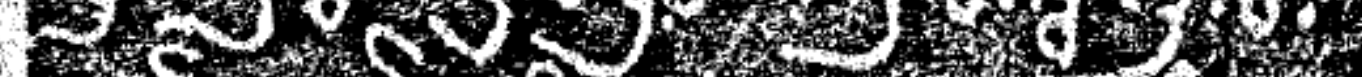

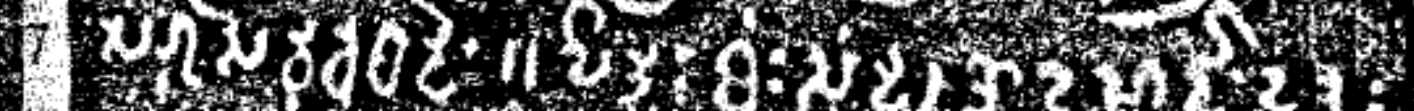

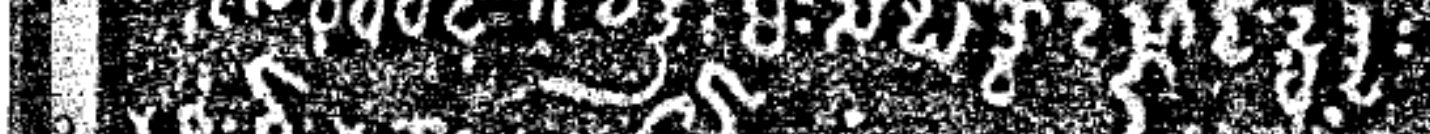

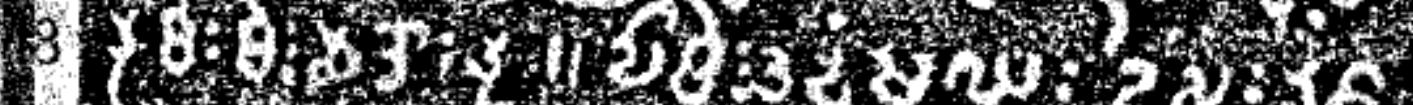

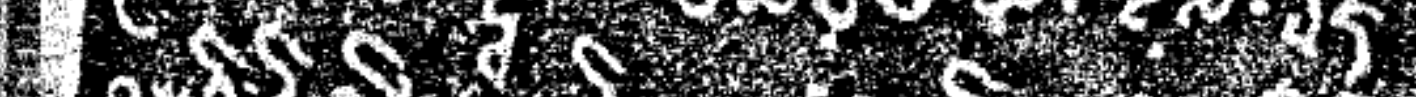

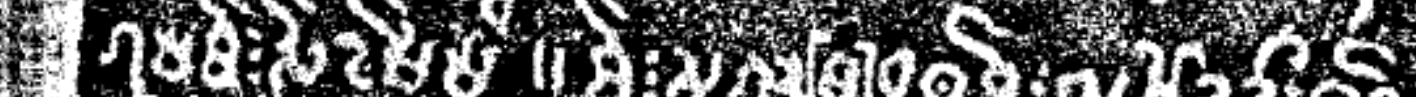

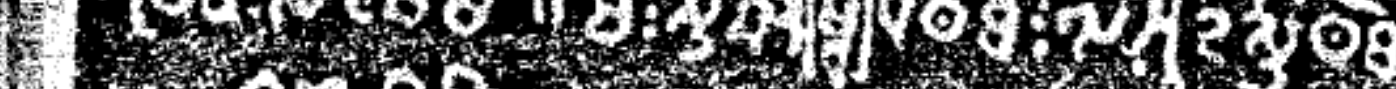

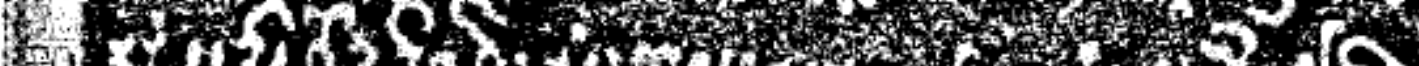

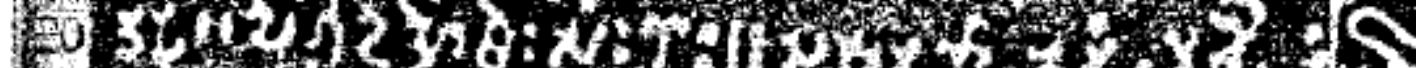
6.

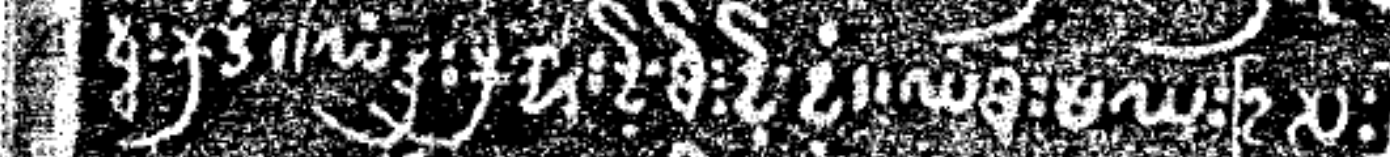

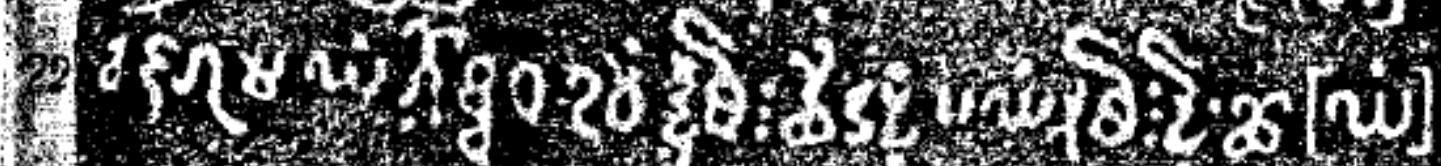

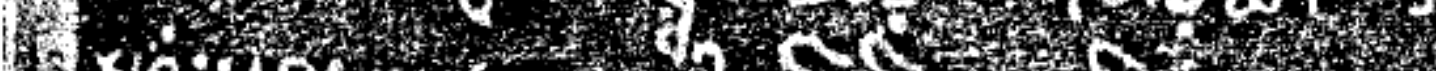

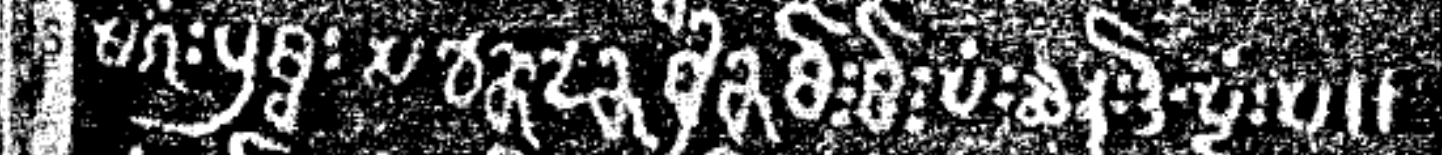

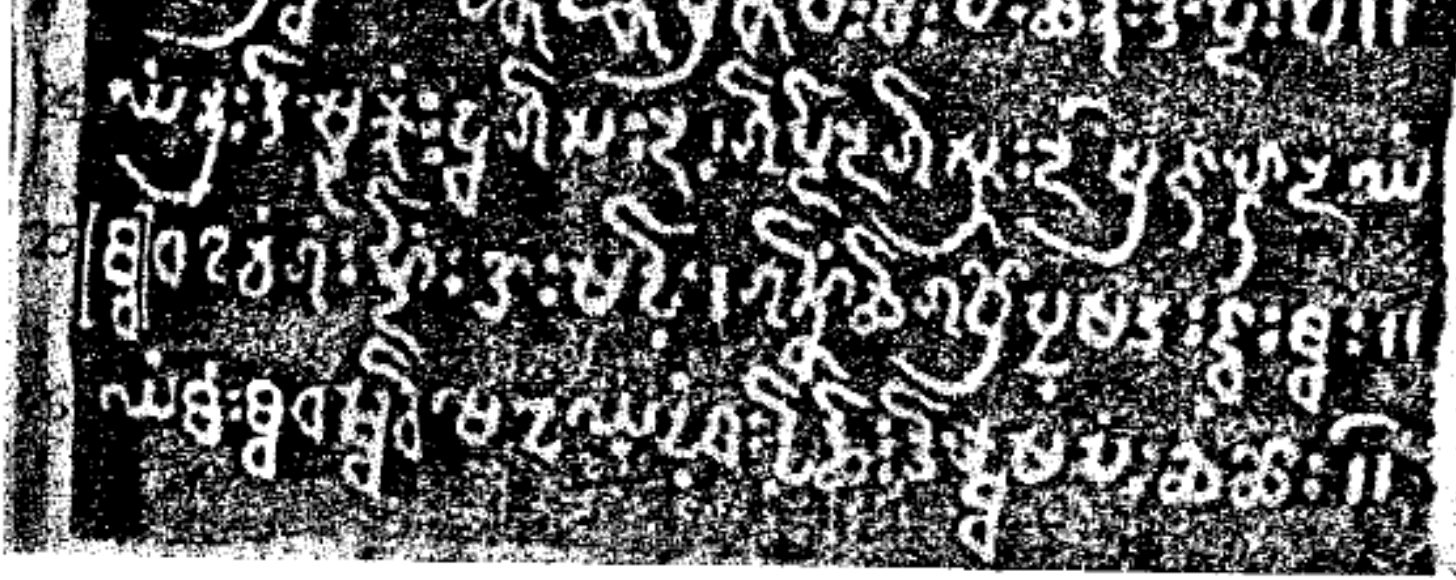




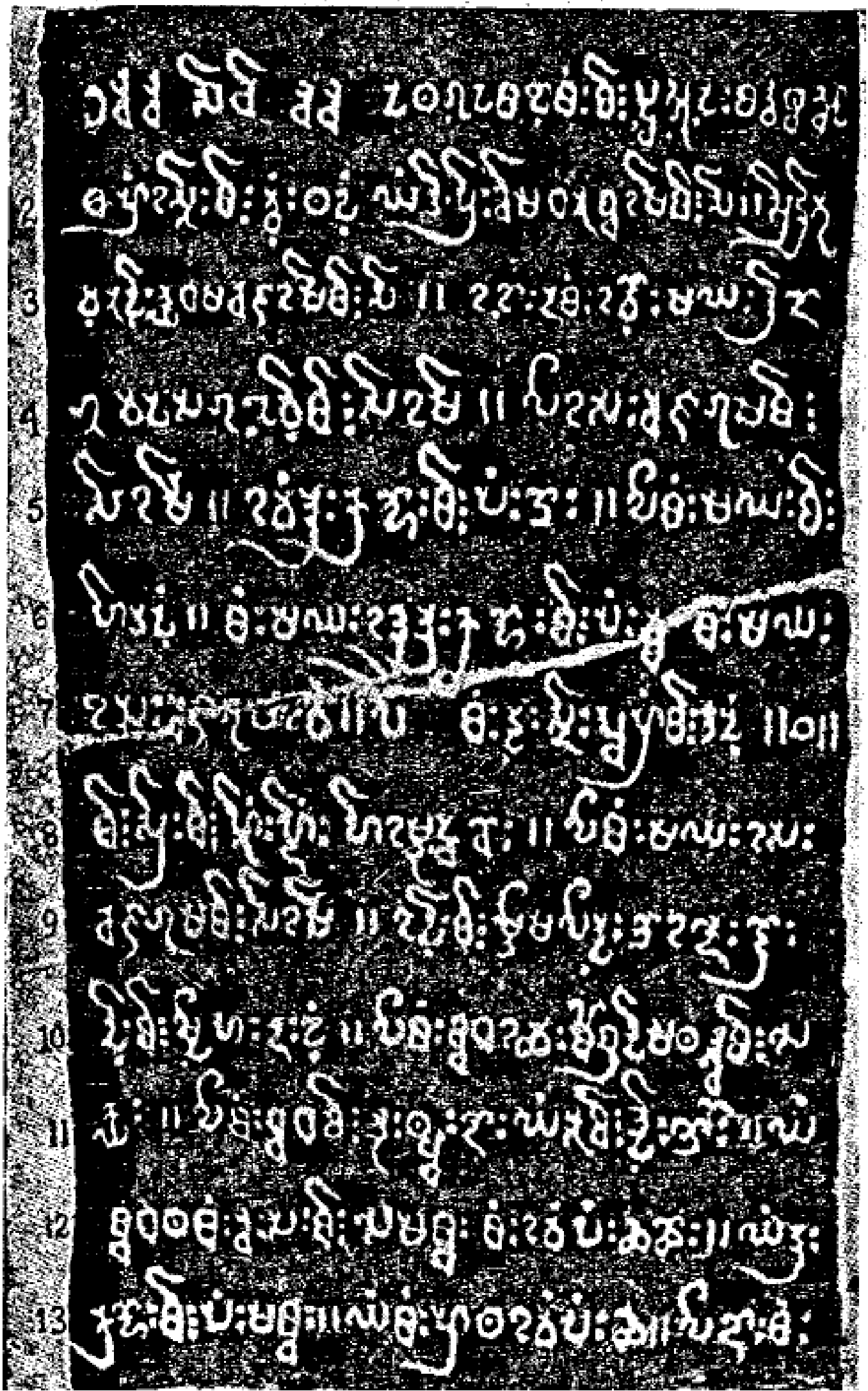




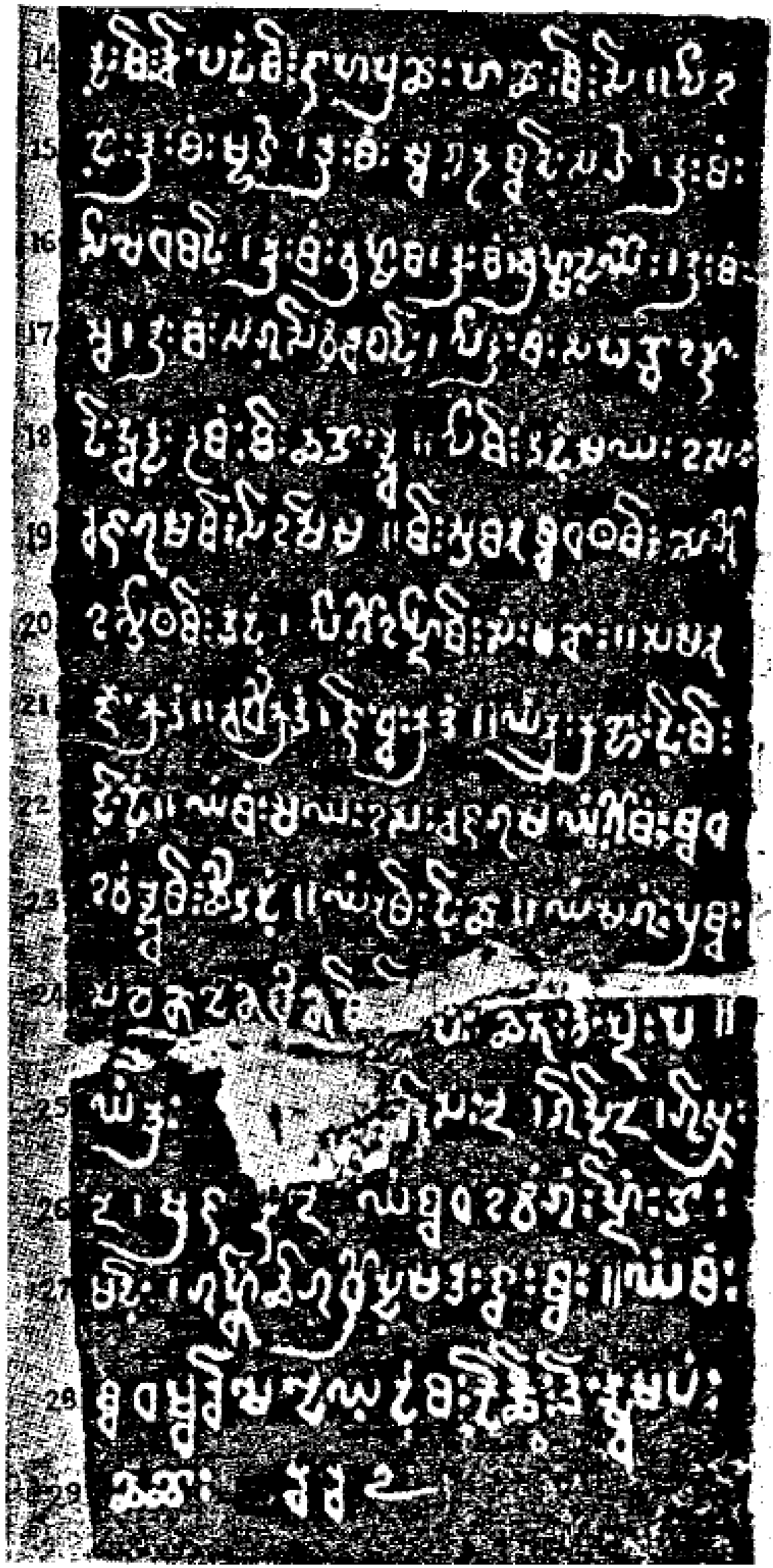

Figure 13. Estampage of PYU 8, lines 14-29 (Tha Myat, 1963, 67) 
The subscript consonants are completely missing from the estampage published in Tha Myat (1963, 66) (Figure 12). The subscript consonants at the start of line two of PYU 8 are circled in Figure 14.

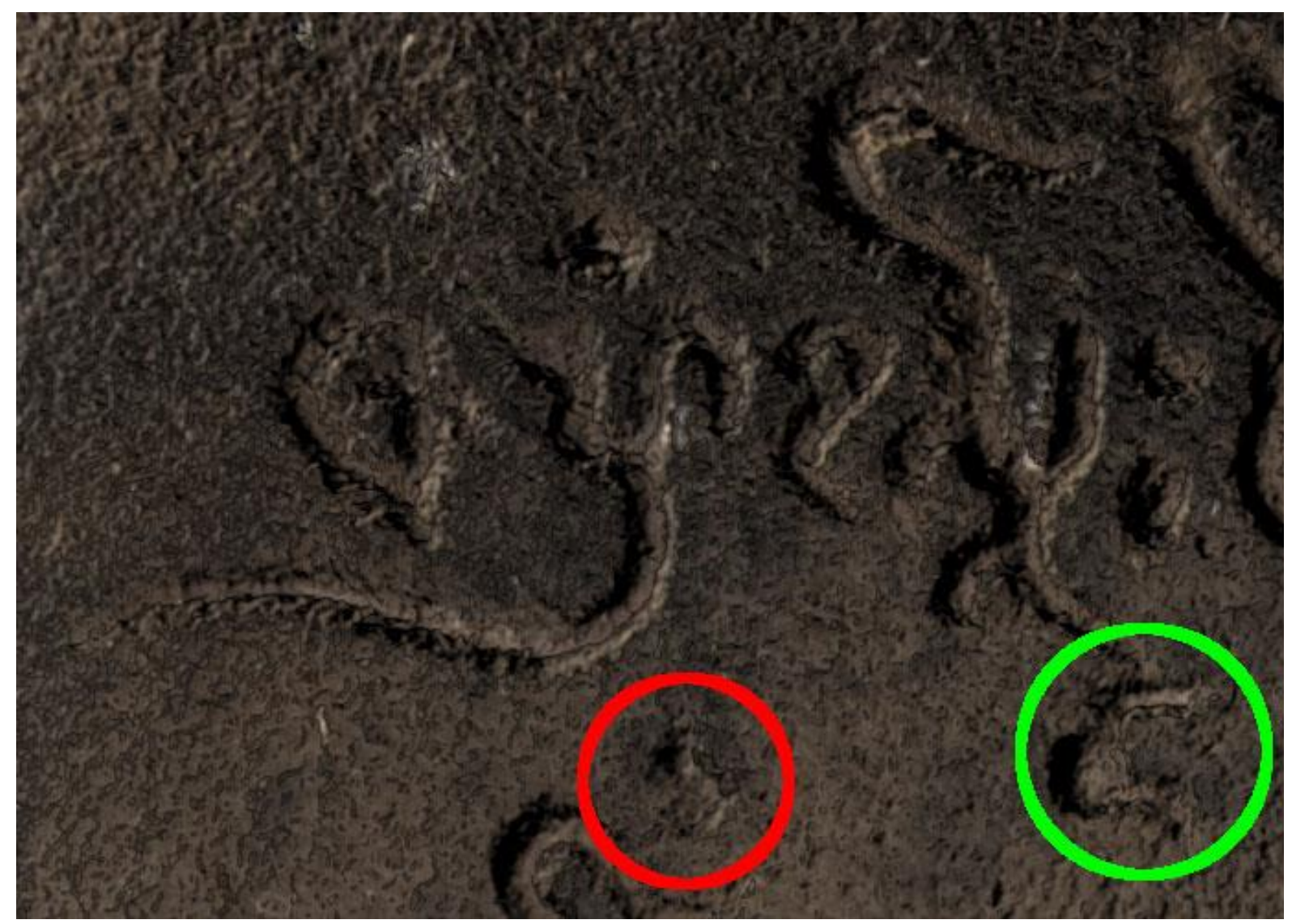

Figure 14. Subscript consonants of hrat.m and snin.h circled in red and green in RTI in diffuse gain

Previous studies identified the first and third syllables in this line as hram 'eight' and snih 'year' without subscript consonants. For decades, the function of the subscript consonants were unclear: Luce $(1985$, I, 62) stated that, "No one, I think, has yet explained this phenomenon, which should (I hope) be not too difficult a task for an Indianist." Three decades later, Indianist Arlo Griffiths identified these subscript consonants as symbols for syllable-final consonants. If Pyu is a TransHimalayan language, we would expect the words for 'eight' and 'year' to end in $t$ and $\dot{n}$ (cf. Old Burmese het. 'eight' and šənin 'year' in Jingpho, another language of Burma (Weidert, 1987)), and those are precisely the consonants that we see in the RTI data. It would be an extraordinary coincidence if the two subscript characters happened to match final consonants in related languages but had some completely unrelated function. The discovery of twelve subscript consonants in PYU 8 has led to the discovery of approximately two thousand more subscript consonants in the rest of the corpus and the rejection of the century-old assumption that Pyu only had open syllables without final consonants. 


\section{Pyu example 2: Tondaw}

The Tondaw inscription (PYU 23) is a geographic outlier in the Pyu corpus. It is the only known Pyu text located in Rakhine State, southwest of Pyu archaeological sites in Upper Burma. It is a $65 \mathrm{~cm}$ high stone menhir standing in the open air atop Phaya Taung hill, near a monastery in the village of Tondaw (Figure 15). The contents of its text are not yet understood. Luce $(1985,1,50)$ speculated it might be potential evidence for Pyu rule in southern Rakhine.

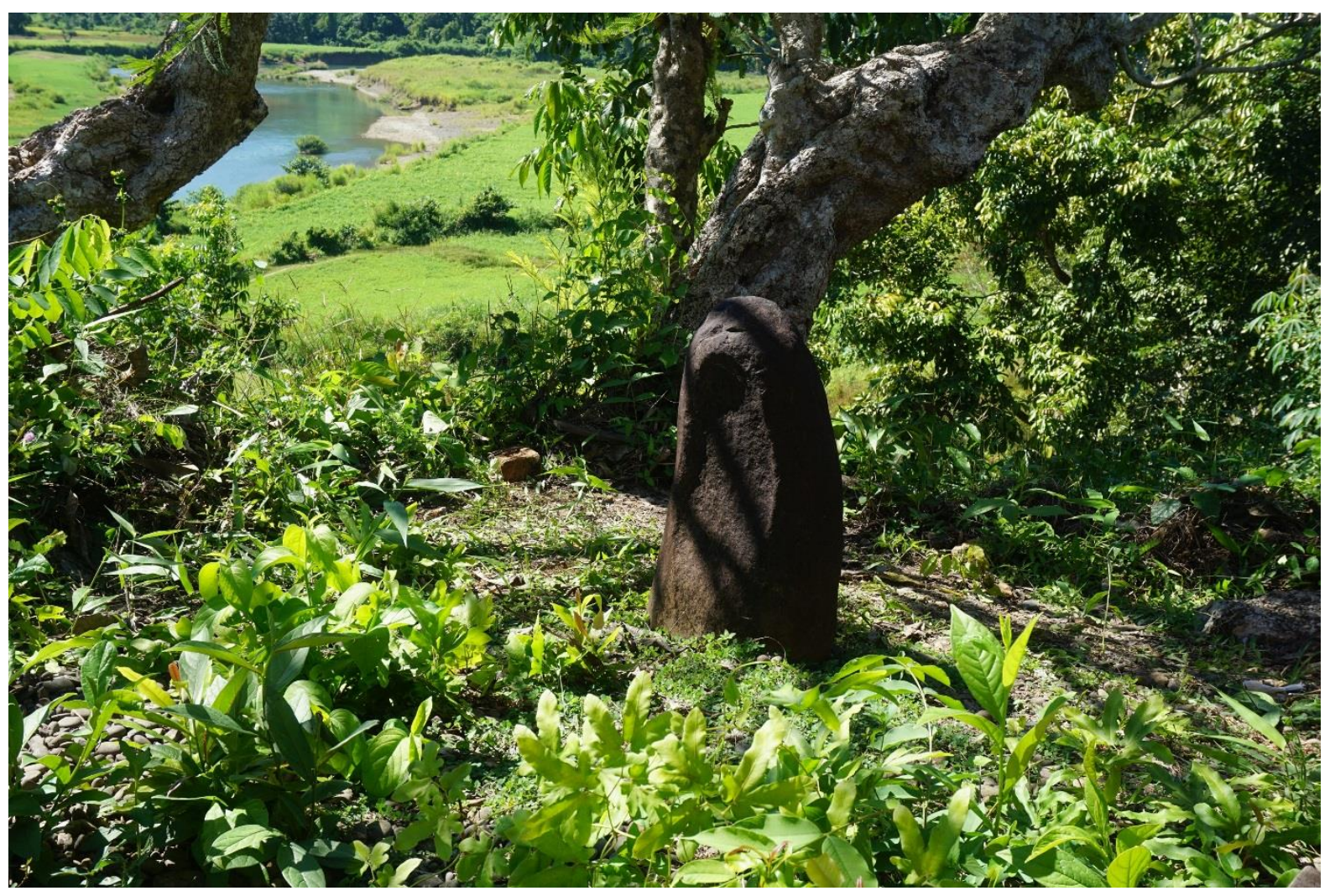

Figure 15. The Tondaw inscription, found atop Phaya Taung hill, near to a monastery in the village of Tondaw. Photo Julian K. Wheatley

Unlike the previous example, the Tondaw inscription is located in the open, curved in shape, and was recorded when a number of shadows from the surrounding trees were draped over the stone. As a result, the recording process for the RTI had to be adapted, with the aperture of the camera narrowed to allow more light, and for project members to cover the stone with an umbrella to remove the unwanted shadow, highlighted in Figure 16. 


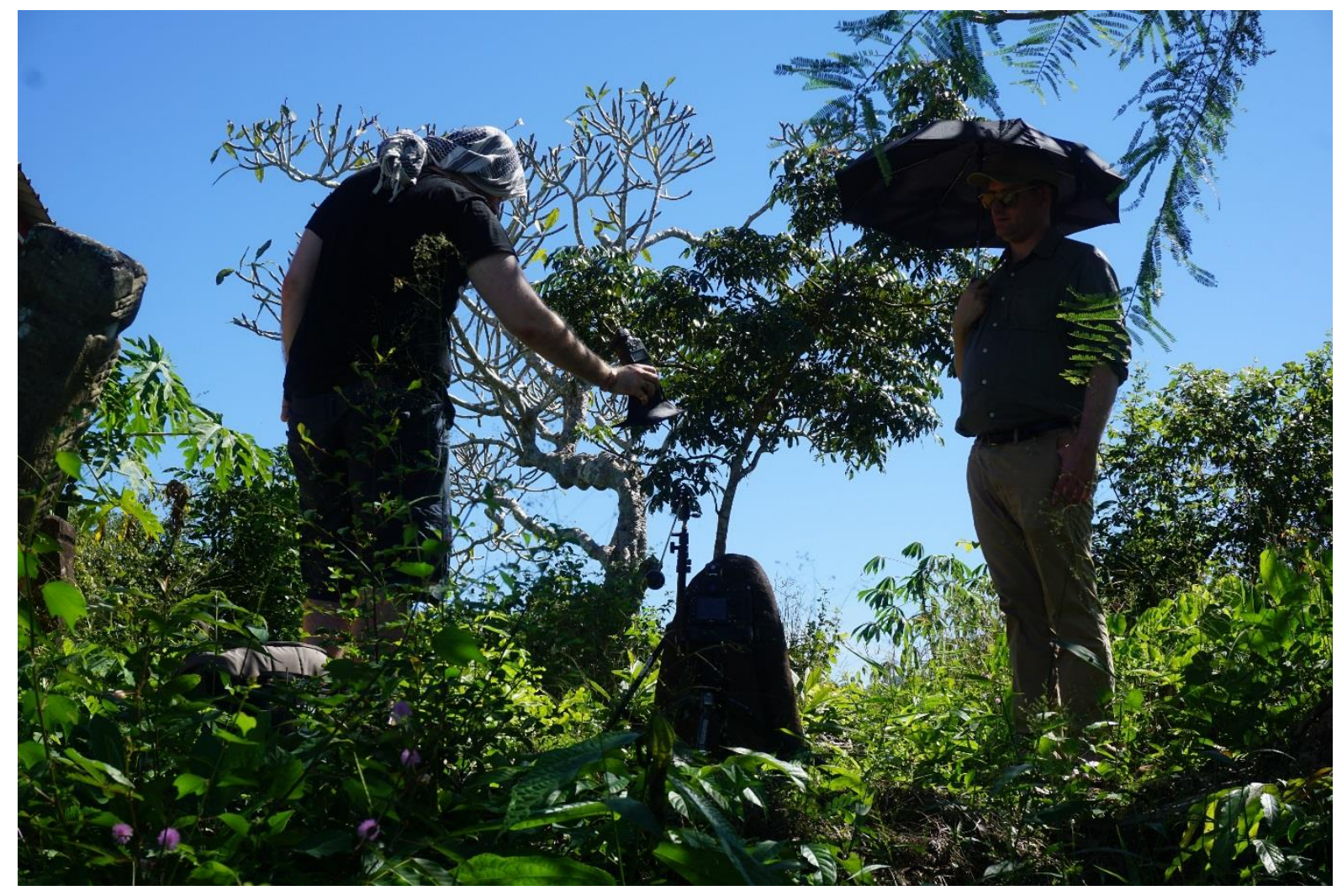

Figure 16. RTI capture of Tondaw inscription. The camera is in a fixed position whilst the external light source (wireless flash) is moved around the stone. The inscriptions are covered by Nathan Hill and the umbrella to remove unwanted shadows in the data capture. Photo Julian K. Wheatley

As the Tondaw inscription was on a curved surface, the results produced differ in quality to the previous examples, but the results are nonetheless useful in examining the Pyu inscription, as highlighted in Figure 17. 


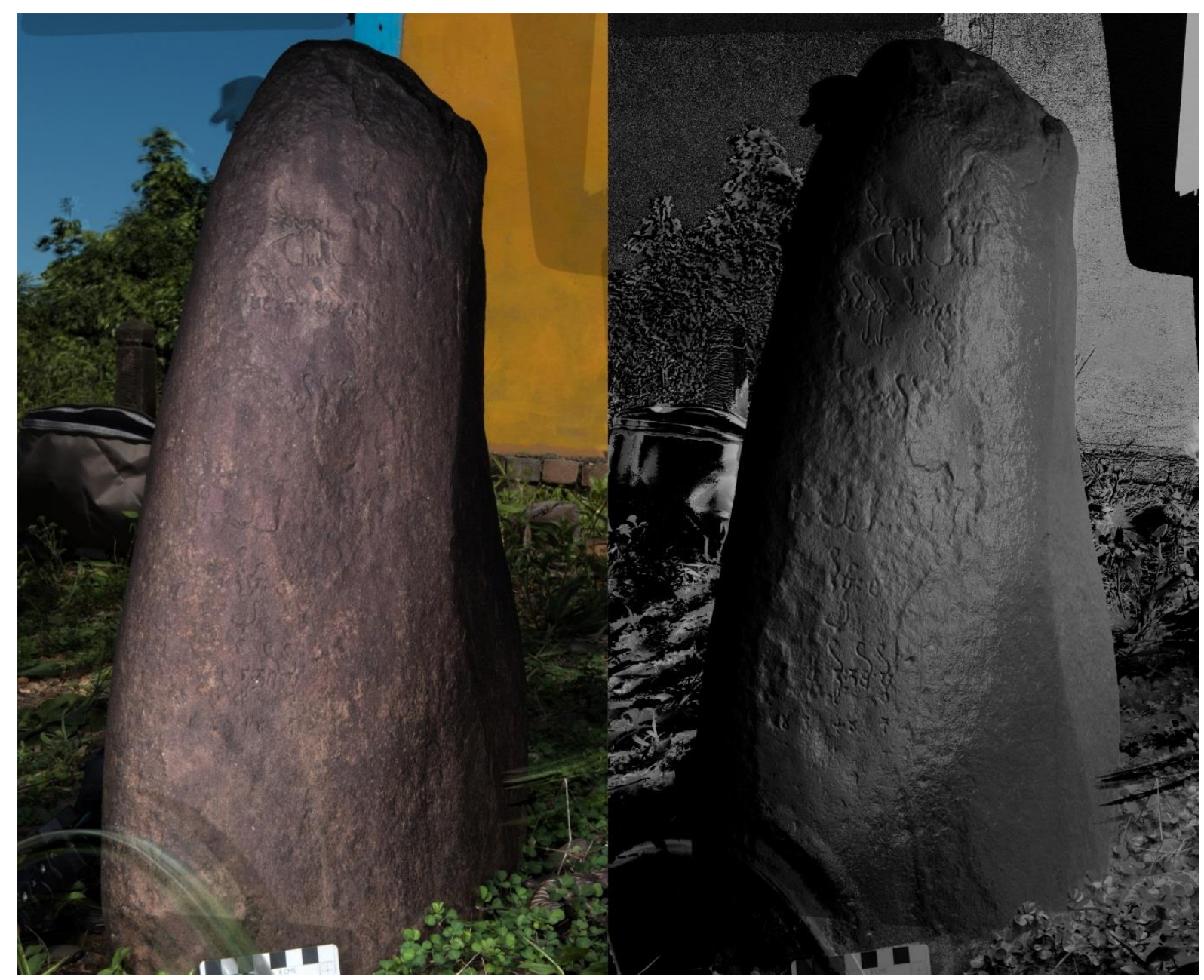

Figure 17. Tondaw inscription. The left image shows the stone under normal lighting conditions, with the inscriptions barely visible. The right image shows the RTI results, under specular enhancement, where the inscriptions are more clearly legible.

\section{Elimination of excessive subscript consonants}

The 1894 eye-copy reproduced in (Tha Myat, 1963, 78) (Figure 18) contains twenty-five misshapen subscript letters that we now regard as consonants. Eight letters do not exist according to our RTI. In Figure 19, the subscript consonants from part of the eye-copy have been superimposed in three colours beneath an image from our RTI: green for correctly identified existent consonants, orange for misidentified existent consonants, and red for non-existent consonants. Consonants in our reading are transliterated in blue. 


\section{Sandoway Pyu}

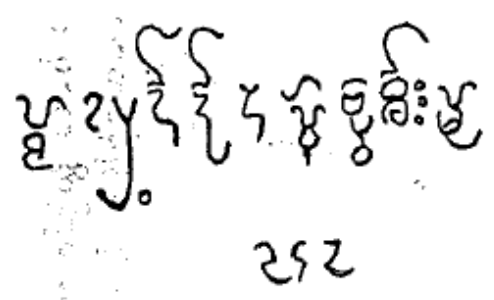

$$
\begin{gathered}
\text { Camp Kyebin } \\
10-9-94 \\
\text { Sd. Maung Me } \\
\text { Myook } \\
\text { Sandoway }
\end{gathered}
$$
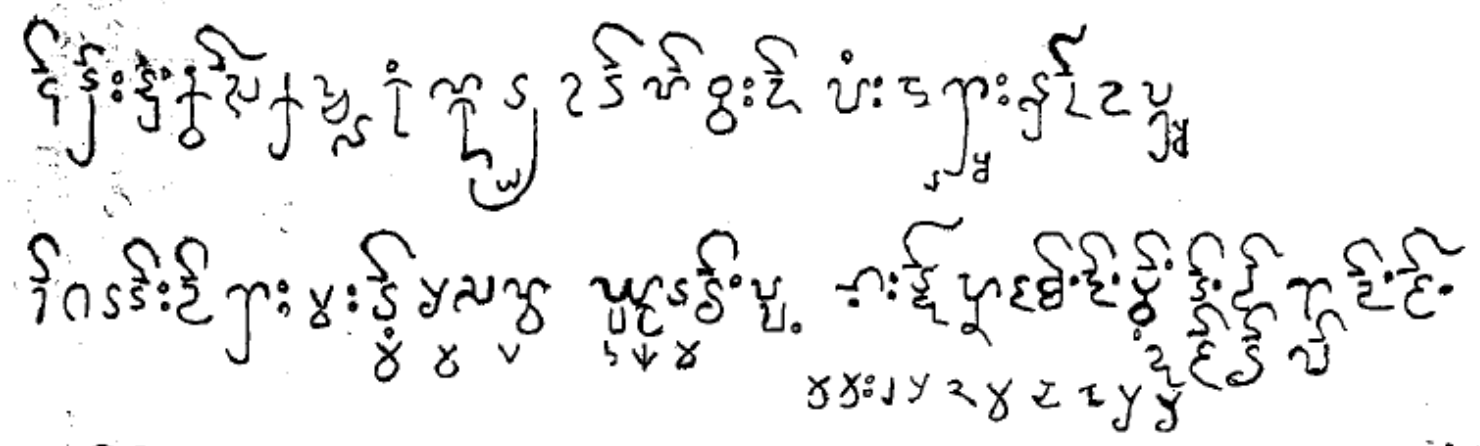

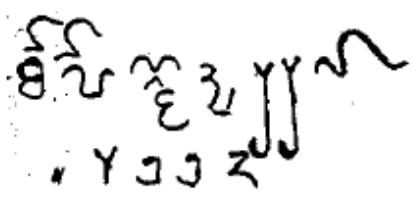

Stone 2 ' $\times \frac{1}{2}$ ' $\times 6$ "' at the village of Tondaw, on Thalu chaung river, about 30 miles from Sandoway town.

"True Copy" Tha Myat 30-7.63
Ref. Rec. No. $517 \quad 12-11-94$

General Department No. $\frac{291}{48-94}$ (Misc.)

A. R. Bricks, Offi; Commissioner, Arakan Division, Akyab,

to Dr. D.E Hubzch Government Epigraphist, Madras, letter Akyab, 29 October 1894.

Figure 18. 1894 eye-copy of the Tondaw Inscription (Tha Myat, 1963, 78)

The 1894 eye-copy predates Blagden's decipherment of the Pyu script and has no transliteration, so at the bottom of Figure 19, a transliteration of the subscript consonants has been provided. Our transliteration is generous: anything vaguely resembling a consonant letter is regarded as such.

All but one of the red characters in the 1894 eye-copy correspond to blank areas in the 2016 RTI; the exceptional $d$. is in a damaged area and could have been lost. It is difficult to understand how those characters could have been smoothed away during the past century.

The orange characters from the 1894 eye-copy may have been miswritten. Symbols resembling the Arabic numeral 2 and $n$. in the eye-copy are revealed as $m$. and $r$. in the RTI. 


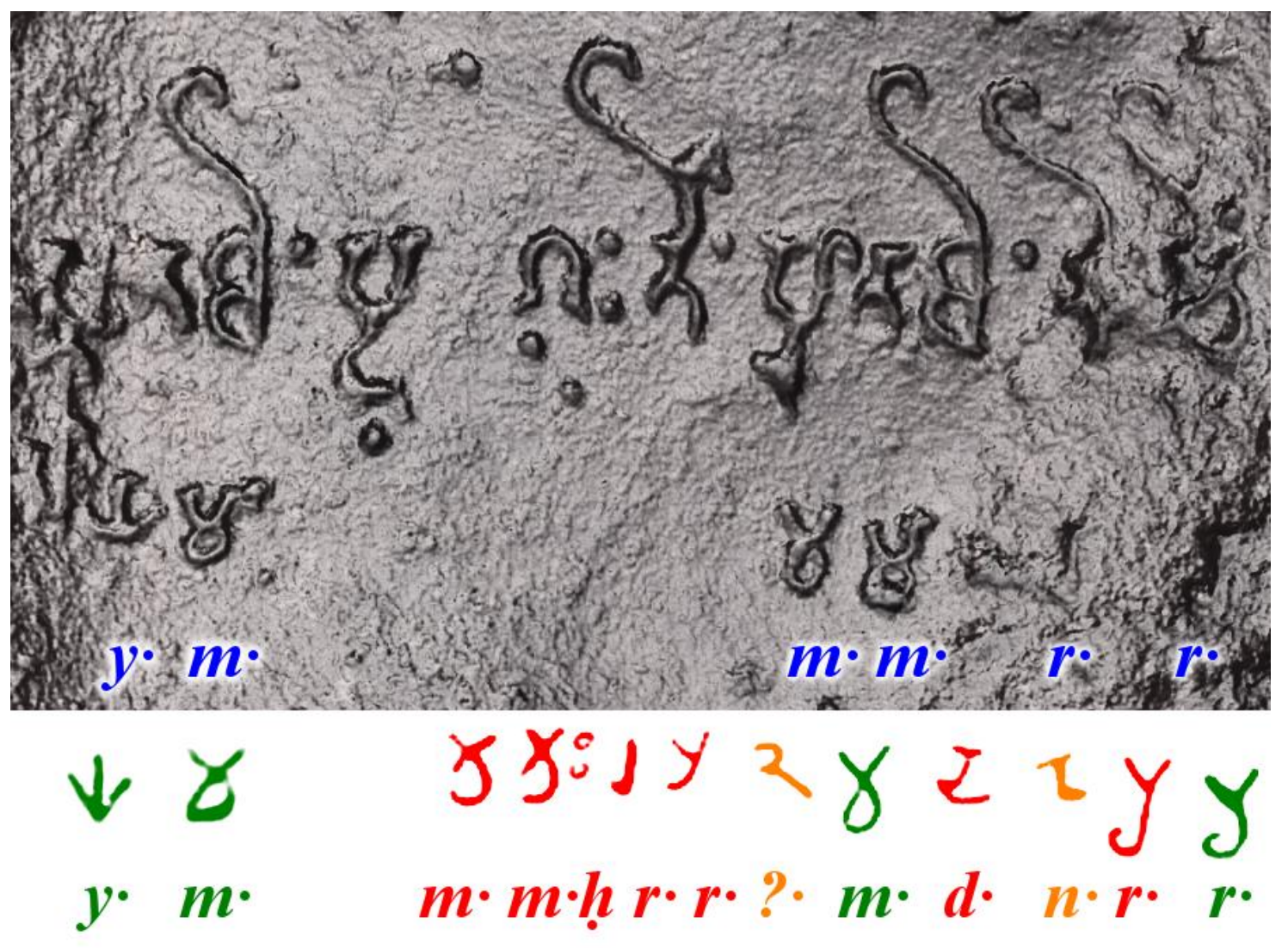

Figure 19. Part of line 5 of PYU 23 in RTI in specular enhancement rendering mode

Although Sein Win (2016, 190-193) had a rubbing of PYU 23 in addition to the eye-copy, he did not see any subscript consonants in the passage in Figure 19, though he did see them elsewhere in the text.

A complete transliteration of PYU 23 from Griffiths et al. (2017a) is found in Figure 20. It contains thirty-three final consonants. Only nine out of twenty-five final consonants in the 1894 eye-copy and four out of eighteen final consonants in Sein Win's (2016) reading have matches in the new transliteration. Even though the eye-copy and Sein Win's rubbing preserve lost passages that may contain final consonants, the new reading still has more final consonants than any previous reading. 

li tim $\cdot \dot{n a y} \cdot t i C \cdot \dot{m} ? ? ? \mathrm{pi}$

\section{Potential of RTI as a tool for epigraphic research}

The majority of Pyu inscriptions are poorly preserved and hard to read. Rubbings of inscriptions are limited in number and cannot reveal the depth of strokes: a deep incision and a light scratch may appear similar on paper. Photographs suffer from similar problems. Eye-copies, still common in Pyu studies, are unreliable.

RTI and photogrammetric data simulate the third dimension missing from earlier formats of documentation. The careful manipulation of light and the different rendering modes in an RTI viewer allow users to gauge the depth of incisions, by seeing their shadows from different angles.

Photogrammetric 3D models allow one to see text on small objects from any perspective in 3D space. Photogrammetry has not been discussed within the paper as it falls outside the scope of our overall intention. The method, however, enables a 3D model to be constructed from 2D images, where depths from overlapping images are combined, to produce a metrically accurate representations. This 3D model then allows for the analyses performed in the RTI to be confirmed, by directly comparing the identified incisions, with their true three-dimensional depths.

This paper has highlighted two of the twenty-one inscriptions that were documented in RTI in Burma during the November 2016 fieldwork season. RTI has revealed previously unseen characters for syllable-final consonants in both the Kubyaukgyi and Tondaw inscriptions. Conversely, RTI has shown that an eye-copy of the Tondaw inscription contains 'ghost characters' absent from the stone.

RTI is not a language-specific technology. It also has great potential for improving the transliteration of inscriptions in other ancient languages such as Old Burmese, Old Mon, Pali, and Sanskrit, which were also recorded during our fieldwork in 2016. The ability to capture high-resolution datasets and 
study the inscriptions in detail away from their original location is beneficial, given limited access to inscriptions, which are often in cramped storage sheds.

RTI is a non-proprietary digital format that can be stored in public-access archives like Zenodo and viewed with open-source software. Burmese institutions and people have the ability to download and interact with RTI data, thus allowing local communities to learn more about Pyu and examine the inscriptions in their full detail whilst on site.

In the future, the adoption of RTI using other light spectra such as infrared and ultra-violet can extract even more subtle features to further aid the transliteration process.

\section{RTIs used}

PYU007_b_1_RTI_cropped_3777.ptm for PYU 8 (007 should be renamed 008) (Miles, 2016b). Tondaw Inscription (PYU023_a_RTI_cropped_3668.ptm) (Miles, 2016a).

A list of recorded Pyu inscriptions can be found on Wikipedia and is being updated with more information as the transliteration process is completed (Hill, 2017).

\section{Acknowledgments}

We are thankful to the Robert H.N. Ho Family Foundation and the European Research Council for funding this project. Likewise, we must acknowledge the work completed by Arlo Griffiths and Julian $\mathrm{K}$. Wheatley in their transliteration of the text provided. We must also thank Bob Hudson for his organisational skills in providing access to the inscriptions and arranging our travel whilst in Burma.

\section{Glossary}

Reflectance Transformation Imaging (RTI): RTI is a computational photographic method that captures a subject's surface shape and colour and enables the interactive re-lighting of the subject from any direction. RTI also permits the mathematical enhancement of the subject's surface shape and colour attributes (Cultural Heritage Imaging, 2012).

Polynomial Texture Mapping (PTM): A mathematical algorithm and image capture and processing technique used in $\mathrm{RTI}$, to enable the recording and representation of subtle surface details.

Specular enhancement: For each pixel, the normal vector can be used in a lighting equation to add either diffuse or specular shading effects to the image. Simulation of specularity is effective at enhancing the perception of surface shape and can be used to remove colour detail pertained in the images used (Malzbender et al., 2001, 525).

Diffuse Gain: Using a Gaussian curvature, the detail of the data recorded in a single image can be increased arbitrarily by a gain factor by computing new luminance coefficients of the data shown, thus incorporating shadow detail from more than one light direction (Malzbender et al., 2001, 525). 


\section{References}

Blagden, C. O. 1911. A Preliminary Study of the Fourth Text of the Myazedi Inscriptions. Journal of the Royal Asiatic Society, 43, 365-388.

Blagden, C. O. 1919. The Pyu face of the Myazedi inscription at Pagan. Epigraphia Birmanica: being Lithic and other inscriptions of Burma, 1, 59-68.

Cultural Heritage Imaging. 2012. Cultural Heritage Imaging [Online]. Available: http://culturalheritageimaging.org [Accessed 1st Novemeber 2017].

Diaz-Guardamino, M., and Wheatley, D. 2013. Rock art and digital technologies: the application of Reflectance Transformation Imaging (RTI) and 3D laser scanning to the study of Late Bronze Age Iberian stelae. MENGA. Journal of Andalusian Prehistory, 4, 187-203.

Duroiselle, C. 1919. The Burmese face of the Myazedi inscription at Pagan. Epigraphia Birmanica: being Lithic and other inscriptions of Burma, 1, 1-46.

Earl, G., Basford, P., Bischoff, A. S., Bowman, A., Crowther, C., Hodgson, M., Martinez, K., Isaksen, L., Pagi, H., Piquette, K. E., and Kotoula, E. 2011. Reflectance transformation imaging systems for ancient documentary artefacts. Electronic Visualisation and the Arts.

École française d'Extrême-Orient. 2017. Corpus of Pyu Inscriptions [Online]. Available: http://hisoma.huma-num.fr/exist/apps/pyu/index2.html [Accessed 20th November 2017].

Goskar, T., and Cripps, P. 2010. Interactive Landscape Relighting [Online]. Wessex Archaeology. Available: http://www.wessexarch.co.uk/blogs/computing/2010/08/26/interactivelandscape-relighting [Accessed 17th January 2012].

Griffiths, A., Hudson, B., Miyake, M., and Wheatley, J. 2017a. Studies in Pyu epigraphy, I: state of the field, edition and analysis of the Kan Wet Khaung Gon inscription, and inventory of the corpus. Bulletin de l'École française d'Extrême-Orient, 103, 43-205.

Griffiths, A., Miyake, M., and Wheatley, J. K. 2017b. Corpus of Pyu inscriptions [Data set]. Zendoo. http://doi.org/10.5281/zenodo.1045546

Hamiel, J. S., and Yoshida, J. S. 2007. Evaluation and application of polynomial texture mapping in the area of shoe and impression evidence. Journal of Forensic Identification, 57, 414-437.

Hill, N. W. 2017. Pyu language (Burma) [Online]. Available: https://en.wikipedia.org/wiki/Pyu_language_(Burma) [Accessed 1st November 2017].

Luce, G. H. 1985. Phases of pre-Pagan Burma: Languages and history, Oxford, Oxford Univ Press.

Malzbender, T., Gelb, D., and Wolters, H. 2001. Polynomial texture maps. Proceedings of the 28th annual conference on Computer graphics and interactive techniques. ACM.

Miles, J. 2016a. Documentation of a Pyu inscription (PYU023) located on the Phaya Taung hill in the grounds of the monastery of Tondaw village, 30 miles from Sandoway town, Arakan [Data set]. Zenodo. http://doi.org/10.5281/zenodo.581300

Miles, J. 2016b. Documentation of the quadrilingual Pyu inscription (PYU007) kept in an inscription shed on the grounds of the Myazedi pagoda in Pagan [Data set]. Zendoo.

http://doi.org/10.5281/zenodo.579873

Miles, J. 2016c. North Boscaswell Mine [Online]. Archaeovision. Available: http://archaeovision.eu/projects/north-boscaswell-mine/ [Accessed 1st November 2017].

Miles, J., Mavrogordato, M., Sinclair, I., Hinton, D., Boardman, R., and Earl, G. 2016. The use of computed tomography for the study of archaeological coins. Journal of Archaeological Science: Reports, 6, 35-41.

Miles, J., Pitts, M., Pagi, H., and Earl, G. 2014. New applications of photogrammetry and reflectance transformation imaging to an Easter Island statue. Antiquity, 88, 596-605.

Mudge, M., Malzbender, T., Schroer, C., and Lum, M. 2006. New Reflection Transformation Imaging Methods for Rock Art and Multiple-Viewpoint Display. In: Arnold, D., Niccolucci, F., Ioannides, M., and Mania, K. (eds.) VAST 2006: Proceedings of the 7th International conference on Virtual Reality, Archaeology and Intelligent Cultural Heritage, October 30- 
November 04, 2006, Nicosia, Cyprus. 195-202. Aire-la-Ville, Switzerland: The Eurographics Association.

Mudge, M., Voutaz, J.-P., Schroer, C., and Lum, M. 2005. Reflection transformation imaging and virtual representations of coins from the hospice of the grand St. Bernard. Proceedings of the 6th International conference on Virtual Reality, Archaeology and Intelligent Cultural Heritage. Pisa, Italy: Eurographics Association.

Pagi, H., Miles, J., Uueni, A., Hogarth, S., and Sikka, K. 2017. Reflectance Transformation Imaging in Daguerreotype Investigation. Archiving Conference, 2017, 116-121.

Piquette, K. E. 2014. Scribal Practice and an Early Dynastic Stone Vessel Inscription: Material and aesthetic implications. In: Dodson, A., Johnston, J. J., and Monkhouse, W. (eds.) A Good Scribe and an Exceedingly Wise Man: Studies in Honour of W.J. Tait. 241-250. London: Golden House Publications.

Ruhemann, H. 1958. Criteria for distinguishing Additions from Original Paint. Studies in Conservation, 3, 145-161.

Selmo, D., Sturt, F., Miles, J., Basford, P., Malzbender, T., Martinez, K., Thompson, C., Earl, G., and Bevan, G. 2017. Underwater reflectance transformation imaging: a technology for in situ underwater cultural heritage object-level recording. Journal of Electronic Imaging, 26.

Tha Myat, U. 1963. Pyu Reader, Rangoon, U Hla Din, The National Printing Works.

Weidert, A. 1987. Tibeto-Burman Tonology: A comparative analysis, Amsterdam, Netherlands, John Benjamins Publishing.

Win, S. 2016. Pyū akkharā cā pe porịh khyup [A collection of writings in the Pyu alphabet], Rheh hoǹ su te sa na nhañ. amyuiḥ sāḥ pra tuik ūḥ sịh țhāna, yañ kyeh mhu van krīḥ ṭhāna [Department of Archaeology and National Museum, Ministry of Culture]. 